POPULAR ART: THE FILMS OF GEORGE ROY HILL

By

EDWARD FRANCIS SHORES

A DISSERTATION PRESENTED TO THE GRADUATE COUNCIL OF THE UNIVERSITY OF FLORIDA

IN PARTIAL FULFILLMENT OF THE REQUIREMENTS FOR THE

- DEGREE OF DOCTOR OF PHILOSOPHY

UNIVERSITY OF FLORIDA

1977 
for Shirley, with love 
ACKNOWLEDGMENTS

No undertaking of this size is an individual effort, and many people have helped me in the completion of this task. Some, though, deserve special acknowledgment.

My parents and family were always supportive, and their love and generosity is a most treasured gift.

My friends, James Goldsmith, Stephen Snyder, Allison Graham, and Barbara Bixby, lent their time, support, and encouragement, making a sometimes burdensome task easier and lighter. I hope I can give as much assistance to them in their future endeavors.

The members of my committee, Dr. Ellen S. Haring of the Philosophy Department, Dr. Ward Hellstrom, and Dr. Motley Deakin gave valuable time and assistance.

Dr. William C. Childers, whose comprehensive knowledge of the cinema proved an invaluable resource, deserves special mention.

Special thanks go to my director; Dr. John B. Pickard, who encouraged the study, and whose criticisms and suggestions helped shape it.

And of course my wife, Shirley, whose love made it possible. 
TABLE OF CONTENTS

Page

ACKNOWLEDGMENTS . . . . . . . . . . . . . . . . . . . iii ABSTRACT. . . . . . . . . . . . . . . V V

CHAPter I: A SURVEY OF THE FILMS . . . . . . . . . . I 1 NOTES . . . . . . . . . . . . . . 28

CHAPTER II: BUTCH CASSIDY AND THE SUNDANCE KID . . . 30 NOTES . . . . . . . . . . . . . . . 54

CHAPTER III: SLAUGHTERHOUSE-FIVE . . . . . . . 56 NOTES . . . . . . . . . . . . . 80

CHAPTER IV: THE STING. . . . . . . . . . . 82 NOTES . . . . . . . . . . . . . . . . 100

CHAPTER V: THE GREAT WALDO PEPPER. . . . . . . 102 NOTES . . . . . . . . . . . . . . . . 118

CHAPTER VI: CONCLUSION . . . . . . . . . . . 121 BIBLIOGRAPHY. . . . . . . . . . . . . . . . I27 BIOGRAPHICAL SKETCH . . . . . . . . . . . . . 130 
Abstract of Dissertation Presented to the Graduate Council of the University of Florida in Partial Fulfillment of the Requirements for the Degree of Doctor of Philosophy

POPULAR ART: THE FILMS OF GEORGE ROY HILL

By

Edward Francis Shores

August 1977

Chairman: Dr. John B. Pickard

Major Department: English

This study attempts to revise the prevailing critical opinion of George Roy Hill by showing that his control of form and content and his use of the medium rank with those of almost any American director. Instead of imitating past conventions, as he is often accused of doing, Hill manipulates them to create his own unique form, a controlled ironic fable that dissects the very conventions it supposedly endorses. Instead of rehashing accepted wisdom or the impoverished dicta of an earlier era, Hill offers his own understanding: He attempts to create the world anew to make it more comprehensible for the viewer. His work evidences the critical intelligence, the craftsmanship, and the intuitive understanding that mark the efforts of any conscious artist.

Hill's films can be seen as a continuing critique of the ideas which have shaped and still support the American culture, questioning such traditional concepts as the nobility of individual heroism, the role and nature of the 
family, and the American obsession with success. His films tell us that these trusted ideas are antiquated; the simple truths they espouse are inconsistent with the more complex modern world. Identification with and acceptance of the concepts does not bring happiness, for an orderly and comprehensible world does not exist; instead, they become lenses that distort perception and lead the individual into limiting, enervating, and occasionally self-destructive actions. In contrast, Hill presents a world where ambiguity, not clarity, is quintessential, and where happiness is not inevitable. He urges a disavowal or dispassionate examination of the cultural conventions, asking that we understand them, and, if necessary, reject them.

Irony is Hill's principle mode of discourse. He weaves variations on his stereotypical characters and plots to create an ambiguity that prevents the easy identification common to most genre films, emotionally distancing the audience from the characters, and making possible a critical evaluation of them and their actions. Each Hill film is both a genre story and an explonation of the genre story, its characters, plot, and metaphysics. The first stands as a frame of reference which allows us to evaluate the variable second, and a perception of their relationship yields an understanding greater than that yielded by either of the parts.

The study examines in detail Hill's last four major films, up to but not including Slapshot, demonstrating how 
Hill controls the cinematic elements to develop both strands of his ironic narrative and moves the viewer toward a greater understanding of the often tacitly accepted culture. 
CHAPTER I

\section{A SURVEY OF THE FILMS}

George Roy $\mathrm{Hill}$ has never been accorded the status given to such older American directors as John Ford, Josef von Sternberg, or Howard Hawks, nor is he ranked with such current Iuminaries as Martin Scorsese, Robert Altman, or Arthur Penn. Such a judgment, however, is neither final nor accurate. As this study will attempt to show, Hill deserves consideration as an American film artist, for his work is a careful meditation on the American culture, an intelligent, continuing exploration of it that ranks with the best contemporary work. The overtly commercial surface of his work masks, but does not obliterate, the intelligence of his films, and his commercial success is a mark of his skill, not his mediocrity. He controls the elements of film to create works that are simultaneously entertaining and serious, and this study will explore the way in which Hill works and the central thematic concerns of his films.

An overview of Hill's career would seem to support the prevailing critical judgment. Hill began with two play adaptations, Period of Adjustment and Toys in the Attic, which, though fairly well received, were not indicative of great cinematic virtuosity. Period of Adjustment is 
essentially a filmed play. The camera is almost always at middle distance, providing a frame like the proscenium arch. The actors move about the frame the way they would a stage, establishing character and ideas through position and dialogue. There is little camera movement, few close-ups, and only functional lighting. Toys in the Attic is a step forwand cinematically, for the camera begins to move, the closeup is discovered, and the lighting helps convey ideas and character. Hill uses the camera to tell the story instead of relying on the conventions of the stage. But in two of his next three films, Hawaii and Thoroughly Modern Millie, there is little evidence of further growth; the camera is only a functional, recording device. Hawaii is a picture postcard film, with the action framed and presented in the traditional Hollywood cinematic grammar; Thoroughly Modern Millie is similar in its traditionality, with well lit sets, unimaginative use of decor, and straightforward camera use. Unfortunately, The World of Henry Orient, Hill's best early film, was unavailable forscreening, and thus it is difficult to make a thorough review of his style. However, on the basis of what is available, it seems safe to say that Hill was not one of the great stylistic innovators.

Thematically, his work also seems conventional. The themes of the plays and Hawaii were set by the original sources, and Hill, while perhaps altering them slightly for public consumption, did not change them in any significant fashion. The World of Henry Orient concerns a young girl's 
growth to maturity, and Thoroughly Modern Millie is solely an entertainment. Hill's work with the thematic concerns of others was competent, a translation to the screen, not a new creation that incorporated the essence of the old. In his original works, only The World of Henry Orient has pretensions to something other than entertainment, and that, although well done, was not seen as the sign of a new, distinctive talent. However, there are two thematic concerns in the early films which are later refined and developed in the later, and thus deserve note. In Henry Orient, Hill deals, in the Peter Sellers character, with posturing and the manipulation of surfaces, a central concern of The Sting and Waldo Pepper. In Thoroughly Modern Millie he plays with the genre conventions of the musical. The manipulation of convention is overt here, done for comic effect, but later it will become a more subtle and integral part of Hill's work. After these first five films, Hill remained virtually unknown. In the increasingly film conscious world of the sixties, Hill's efforts seemed part of an outdated commercial tradition. He went to successes from the stage or novel, or tried-and-true genre formulas, to guarantee himself an audience, and appeared to lack an intrinsic interest in film as an aesthetic phenomenon. New directors, on the other hand, were becoming more conscious of the film tradition, and using and commenting on it in their works. They were concerned with style, experiential reality, studies of the human spirit, or creating their own unique world. ${ }^{1}$ Critical acclaim went 
to the imaginative explorations of Antonioni, Fellini, Bergman, and the New Wave of French directors; American directors like Siegel and Bogdanovitch were touted, early directors rediscovered, critical theory was pushed in new directions, and politics was made a criteria of film excellence. Commercial films like Hill's seemed to belong to an appreciated, but no longer relevant past.

In 1969, Hill released Butch Cassidy and the Sundance Kid, an enormously popular and successful Western that seemed proof of Hill's commercial craftsmanship and conventionality. His subsequent efforts, Slaughterhouse-Five, The Sting, The Great Waldo Pepper, and Slapshot all received similar critical treatment: A perfunctory acknowledgment of the craftsmanship and a sign that such efforts were being put into commercial exploitation. Hill's position as a talented, "studio" type director seems fixed, and he is currently relegated to the status of Sidney Lumet, Arthur Hiller, or older studio reliables like Mervyn LeRoy or Michael Curtiz. There seemed little to praise in his works, for they were traditional in their scope and even crassly commercial in their aims. The subjects and treatments were familiar and lacked the sense of innovation or self-conscious use of the medium that characterized the best new work. The more serious of the American popular reviewers--Pauline Kael, John Simon, Stanley Kauffmann, Andrew Sarris--praised overt attempts to use the medium to aesthetic ends. Robert Altman's experiments with genre and the element of narrative 
and sound, Arthur Penn's thematic concerns, Martin Scorsese's ventures into the underside of America or into Hollywood genres, Francis Ford Coppola's unique vision--these received critical approbation.

The European critics apparently found Hill equally uninspiring. To critics and filmmakers concerned with the past and film form, such as Godard and Truffaut, Hill's works must have seened unimaginative exercises in commercialism. Nor did his works have the strong stamp of an auteur who rose above the restrictions of the commercial film system. To those critics increasingly concerned with politics--the Screen magazine coterie in England, the Cahiers du Cinéma group in France--Hill's work must seem anathema. His films focus exclusively on individuals, not on the masses, and tend to depict the crowd as the lowest, most vulgar element of the human species. There is absolutely no concern for political issues, or the place of cinema in the class struggle for revolutionary liberation. ${ }^{2}$ In fact, Hill's films possess none of the great virtues of all revolutionary films--narrative intransitivity, estrangement, foregrounding, multiple digesis, aperture, unpleasure, and reality--enumerated by Peter Wollen. ${ }^{3}$ His films are straightforward, entertaining, and comprehensible examples of the "reactionary boungeois capitalist cinema."

This study attempts to revise the prevailing critical opinion of Hill by showing that his control of form and content and his use of the medium rank him with almost any 
American director. Instead of imitating past conventions, as he is often accused of doing, Hill manipulates them to create his own unique form, a controlled inonic fable that dissects the very conventions it supposedly endorses. Instead of rehashing accepted wisdom or the impoverished dicta of an earlier era, Hill offers his own understanding: He attempts to create the world anew, as every artist must, to make it comprehensible for the viewer. His work evidences the critical intelligence, the craftsmanship, and the intuitive understanding that mark the efforts of any conscious artist. Whether or not Hill's judgments and understanding will stand the test of time remains to be seen, but his best work is an intelligent cinematic exploration of the American experience.

This study will focus on his last four major films-Butch Cassidy, Slaughterhouse-Five, The Sting, and Waldo Pepper--,for they are free of non-cinematic influences and representative of Hill's best work. The five early films are not included, not only because they lack the maturity of the later, but because inclusion would only extend, not alter, the basic points of this study. Slapshot, Hill's tenth film, was not included because there was not enough time after its release to give it a detailed treatment. Some observations on it, however, are included in the "Conclusion."

Hill's films can be seen as a continuing critique of the ideas which have shaped and still support the American 
culture, He questions such traditional concepts as the nobility of individual heroism, the role and nature of the family, and the American obsession with success. These concepts are a small part of a core of ideas that can be termed "conventional morality," wisdom that, whatever its origins, comes to be accepted as given by the members of a culture. The configuration of this morality is ambiguous, but a suggestive and subjective outline can be drawn. The conventional wisdom with which Hill's films deal holds that the forces of good invariably triumph over the forces of evil; that righteousness is rewarded while wrongdoing is punished; that the universe is providentially and benevolently ruled; that the family is a strong force for good; that violence, if channeled in socially approved directions, is acceptable; that union with society is a person's most important goal; that the development of the individual spirit is a person's most important goal; that acts of heroism are meaningful and add to a person's stature; that marriage is the ideal relationship between two people; that success marks an individual; and that material success is secondary to emotional happiness. The list could be extended, but this at least suggests what is meant by conventional morality.

of course, these ideas have been attacked by filmmakers from the $1930^{\prime} \mathrm{s}$ on. More recently, Arthur Penn's Bonnie and Clyde and Sam Peckinpah's The Wild Bunch both exploded traditional concepts of violence by revealing the gore which previous Hollywood films had glossed over. Films 
about failures, such as Bob Rafelson's Five Easy Pieces, or unconventional heroes, such as William Friedkin's The French Connection reaped financial success, and films that concentrated on the seamier side of life were no longer taboo. Midnight Cowboy dealt with a derelict and a male prostitute; Klute had a female prostitute as a heroine; and Easy Rider focused on two drug dealers. Directors began to play with conventions, using them to other ends than those for which they were originally intended. Roman Polanski's Chinatown both parallels and departs from the conventions of the detective thriller, and suggests a decidedly different understanding of evil than that found in most private eye films. Robert Altman's McCabe and Mrs. Miller and Arthur Penn's The Missouri Breaks both show an underside of the American experience that was never captured in the traditional Western films which theirs imitiate.

Despite the proliferation of such efforts and a general shift in attitude away from the optimism of the thirties, the postwar hope of the forties, and the television world of the fifties, the traditional film and the conventional morality remain firmly entrenched. The cultural unity that permitted the development of the Hollywood entertainments may no longer exist, but the conventional narratives and morality still exert a great attraction for the majority of Americans. Walt Disney's efforts still meet with considerable success, and "traditional" stories, if done well, can expect to reap a profit. The Sound of Music, 
Mary Poppins, A Star is Born (1977), Jaws, The Other Side of the Mountain, and Rocky have all done well with the public despite their lack of innovation or great artistry. The industry's most recent success, Star Wars, seems a hit precisely because it captures the optimism, enthusiasm, and simplicity of an earlier era.

Hill, like Altman, Penn, and Polanski, challenges these still prevailing concepts of conventional morality. His films tell us that these trusted ideas are antiquated; the simple truths they espouse are inconsistent with the more complex modern world. Identification with and acceptance of the concepts does not bring happiness, for an orderly and comprehensible world does not exist. For Hill, these concepts are lenses that distort perception and lead the individual into limiting, enervating, and occasionally self-destructive actions. In contrast, Hill presents a world where ambiguity, not clarity, is quintessential and where happiness is not inevitable. He disavows or dispassionately examines the cultural conventions, asking that we understand as well. as accept them, and, if necessary, reject them. He calls, in essence, for a new independence, a personal determination of one's attitudes, aims, and understanding. His films, like those of most critically acclaimed new directors, stand as a challenge to the old ways of seeing and defining self.

Hill's films contravert conventional thought through irony. He weaves variations on the stereotypical characters 
and plots in with the conventional action to give his stories more substance and depth. The contrast between the familiar genre story and the variations creates an ambiguity that prevents the easy identification common to most genre films. The ambiguity emotionally distances the audience from the characters, and makes possible a critical evaluation of them and their actions.

Each Hill film has two stories: (1) a genre story, and (2) an exploration of the genre story, its characters, plot, and metaphysics, much as Godard's Breathless is, in James Monaco's words, "at one and the same time a Gangster story and an essay about Gangster films." "5he first stands as a frame of reference which allows us to evaluate and understand the variable second, and a perception of their relationship yields an understanding greater than that yielded by either of the parts. " As Leo Braudy says, "genre in films can be the equivalent of conscious reference to tradition in the other arts." ${ }^{7}$ The use and variation of conventions is one way the artist can get at the metaphysics of a traditional form. Braudy writes that "the possibility exists in all art that convention and comment coexist, that overlapping and even contradictory assumptions and conventions may be brought into play to test their power and make the audience reflect on why they were assumed." 8

The process is instantaneous, hardly as prolonged as the description, as a few examples will show. In Mel Brooks' Blazing Saddles the cowboys solemnly gather around the 
campfire to eat beans, a scene immediately reminiscent of many in earlier Western films. When the cowboys suffer from gas, the audience laughs, not only because the bathroom humor appeals to many, but also because the second scene is a witty variation of the genre scene. The two are essentially juxtaposed for us, and the continguity yields an additional humor. We realize that the early Hollywood scene was unrealistic in its glossing over of natural body functions, and we laugh because the exaggerated variation ridicules the unwarranted modesty. In Robert Altman's $M * A * S * H$, the hospital scenes are much more realistic than those found in most Hollywood war films. The conventional, antiseptic pain of the earlier films serves as a point of reference, and the contrast between the two reveals the essential falsity of the Hollywood treatment of war. The characters function in the same way. Hawkeye and Trapper John, despite their self-interest and lack of overt courage, seem much more realistic and human than, say, the John Wayne character in Back to Bataan.

In addition, films are occasionally less obvious in their manipulation of genre conventions. Leo Braudy notes that:

The genre film lures its audience into a seemingly familiar world, filled with reassuring stereotypes of character, action, and plot. But the world may actually not be so lulling, and, in some cases, acquiesence in convention will turn out to be bad judgment or even a moral flaw--the basic theme of such Hitchcock films as Blackmail (1929), Rear Window (1954), and Psycho. . . . The very relaxing of the critical intelligence of the 
audience, the relief that we need not make decisions--aesthetic, moral, metaphysical--about the film, allows the genre film to use our expectations against themselves, and, in the process, reveal to us expectations and assumptions that we may never have thought we had. 9

Altman's McCabe and Mrs. Miller, Hal Ashby's Shampoo, and John Schlesinger's Darling all work in this manner. I would contend that Hill's films work the same way: Perception of the alternate story comes only through careful attention to detail, and understanding only when we see the complex relationship between original and variation. In order to show how Hill's films work, I shall first sketch in the variations of the standard story that prevent complete identification with the characters, then broadly outline the elements of Hill's alternate story, and finally draw some conclusions from an examination of the two.

All Hill's works belong to the category of commercial movies, films which, despite their variety, have remarkably similar characters, structures, and morality. In these films, representative characters resolve problems or achieve happiness by voluntarily accepting and practicing the tenets of conventional morality. The characters may begin outside society, such as Harry Morgan in Hawks' To Have and Have Not, the iconoclastic Fred Astaire figure in the musical comedies, or the classic Western hero, such as Tom Donaphon in The Man Who Shot Liberty Valence, and then move to a reconciliation with society, or remain outside society but essentially endorse its values. Or the character may begin 
as a member of society and then reaffirm its power by using its values and resources to defeat an enemy. Whatever the case, the characters usually move through a series of trials, eventually finding happiness through acceptance of conventional morality. The films thus become implicit or explicit advocates of the American culture; entertainments, but nonetheless assertions of the fundamental validity of certain values.

Although Hill's films seem produced from this mold, they are more accurately variations of it. Ideally, and this is true in such recent commercial ventures as Rocky, Jaws, and The Exorcist, the central characters, no matter what their Iimitations, ultimately embody a number of virtues with which the audience can identify and toward which it can feel sympathetic. Loyalty, courage, integrity, friendship, moral character are emphasized or, more often, emerge as the character undergoes a series of trials: town drunks reform, failures succeed, refugees from love become romantic, uncommitted figures turn patriotic, cowards gain courage, and sinners repent. The protagonists draw us into the world of the film and allow us to experience vicariously the emotions around which the film is structured; we intuitively learn through them the lessons of the film. Hill's characters, like all genre figures, have attractive qualities which draw us to them, and their problems--conflict with an increasingly bureaucratic or technological world, or a dispirited or materialistic one--engage our sympathy. But 
complicating the familiar frame are flaws that prevent total identification. Eventually the protagonists demonstrate some weakness, insensitivity, or failing that negates their hold on our feelings, drawing instead our wonder or disapprobation. We begin to question the characters, and in that questioning move away from the unthinking stock response. In addition, these flaws, unlike those of traditional characters, are never truly overcome; they stay with the characters throughout and, by virtue of their presence, contribute to our sense of ambiguity. The weaknesses are sometimes well-hidden, as in The Sting, or obvious, as in Waldo Pepper, but are always an integral part of the film.

The outlaw heroes of Butch Cassidy are loveable, charming, attractive figures whose stereotypical strengths are counterpointed by their seemingly limitless capacity for bad judgment. As the film progresses, their inability to see the hopelessness of their situation becomes a mark of their limitation, not their charm. Any sympathetic judgment is qualified by recognition that their independence is as much stumbled into as chosen; they do not understand the consequences of their actions. They contrast dramatically to the characters in The Wild Bunch, who decide to adhere to their old values rather than submit to the new technological world. Before the climactic shootout, Pike and Dutch exchange glances, indicating that they know the probable outcome of returning for Angel, but accept those consequences of their actions. 
Billy Pilgrim is an engaging, but impotent naif who accepts prisons, such as life in Ilium, with a perseverance that borders on masochism. He lacks the ability or initiative to solve his problems, and accordingly his "triumph" on Tralfamadore is more accidental and fantastic than earned. Despite our sympathy for him, he never becomes competent or strong enough to draw our identification. Hooker and Gondorff are roguishly charming con men, but no charm can hide the fact that the sting is performed as much for self-gratification as for revenge. At the end of the film, they deny that justice, the motive that has sanctioned their actions and made them more sympathetic than Lonnegan, is attainable or even worthwhile. This last minute reversal mutes some of our strong feelings for them and negates an unthinking emotional response to them.

While Waldo Pepper emerges victorious over Kessier, his road to that victory seems accidental, not earned. In addition, his lie about the fight with Kessler, his inability to learn from the experiences of his friends, and his failure in the attempted rescue of Mary Beth are qualities inconsistent with those usually associated with heroes. Once again the complete identification customary in commercial film is lacking. Reggie Dunlop, of Slapshot, demonstrates few of the virtues we expect to find in a conventional protagonist. There is no sensitivity or understanding hidden beneath his rough exterior; the crudity is the man. The championship cannot disguise the fact that 
Dunlop has manipulated the emotions of his players, ruined his own marriage, and almost destroyed the neurotic Lily Braden.

The variations in character, which suggest an additional dimension to the films, are adumbrated and buttressed by the variations in structure. In conventional films, the character moves from a state of tension or estrangement to one of hammony and order through acquiesence to the conventional morality. Whatever problems the characters encounter are eventually resolved by an appeal to the precepts of traditional wisdom. They (and we) learn the "proper" way to act and think, and the world becomes clearer and less threatening. In John Ford's The Man Who Shot Liberty Valence, for example, Ransom Stoddard, and the civilization which he both endorses and represents, is threatened by the anarchic violence of Liberty Valence. Stoddard refuses to use force, attempting instead to break Valence's hold through the law, education, and the press. When that fails, he eventually learns that socially approved violence must establish civilization. Though violence is dishonorable and may be a part of civilization, it is occasionally necessary, to defend society. Those who practice violence are honored, but by their very nature excluded from society. Other Western films, like George Stevens' Shane, preach the same concepts, as did almost all Hollywood war films. Gangster films almost always begin with the criminals in the ascendency, move through periods of greater criminal success, 
and usually end with the criminal a victim of his own arrogance or other failings, and the law victorious because of its superior intelligence or moral strength. Evil, it seems, contributes to its own destruction, while the law is by its nature triumphant. Whether or not crime is actually that simple is beside the point; the movies usually portrayed it in that manner. Romantic films usually involved some separation of the lovers, or some basic misunderstanding, as in Top Hat, that had to be overcome before the happy conclusion of marriage. Films like Mildred Pierce, Imitation of Life, and Young Man with a Horn depicted people attempting to achieve success. Those characters usually reached their goal, but lost the much more valuable spiritual wealth of family and friends that has almost always been endorsed in popular culture. At the end, they usually recognized this commonplace of conventional wisdom and learned a bitter lesson, or else were reprieved and given another chance. The variations of the commercial story are endless, but the basic structure remains the same: Those who accept conventional morality gain happiness.

In Hill's films, this basic structure is reversed. The characters have problems because they accept the dictates of conventional wisdom, not because they have cut themselves off from it. They begin as firm adherents to some quintessentially American belief and untypically move to a state of estrangement or tension because of their adherence to that belief. Such a basic reversal of structure alters the 
thematic thrust of Hill's films. Conventional morality hinders, not aids the comprehension of the world, and consequently its validity is undercut.

In Butch Cassidy, for example, the outlaws are prime examples of American individuality. They reject the closed technological society and insist on their right to lead their own lives. Ordinarily such an attitude would be supported or shown as a source of strength, but Hill shows their blind adherence as a weakness leading to death. Their inability to see that the concept of unfettered individualism is no longer valid destroys them. Waldo Pepper and Reggie Dunlop are typically American in their pursuit of excellence and success. Identification with them is easy because their desire has been bred into most Americans through schools and social institutions. But, unlike the traditional heroes, their desire for success leads to troublesome dilemmas, and their "triumphs" are of such an ambiguous nature that we question, rather than applaud, their achievements. Billy Pilgrim starts with an unshakable belief in the sanctity of the American family, an institution long dear to social and religious leaders. But Billy finds only unhappiness with his families; the strength that should theoretically support him is inadequate or nonexistent. Even his rescue by Tralfamadore, because fantastic, underscores his failures with his earth families. The characters in The Sting begin with the traditional belief that there should be equal justice for all, even those who are seemingly beyond the law. 
But that attitude causes serious problems, and the two con men end up rejecting the validity of the traditional notion to assert that self-gratification is equally important.

Once we recognize that Hill's films are not crass imitations of traditional works, we can perceive the outline of the world present in his films. In his universe the individual has become burdened with cultural misconceptions. The culture has shaped his attitudes in such a way that the individual can conceive of discovering meaning and attaining happiness only through the attainment of certain preordained goals. For him, prescribed rituals, such as the performance of a heroic action, lead to the prescribed results of respect and reward. The cultural concepts are so dominating that the individual cannot conceive of alternatives, and thus the concepts occasionally become more valuable than Iife itself. Worse, Hill argues, the concepts are antiquated, describing fixed relationships that no longer apply to a fluid, changing world, and, at their worst, absorbing the individual.

A review of the conflict in each film shows that it is the individual's belief in a concept that is the source of trouble. Butch and sundance are trapped by their belief in the nobility of heroic individualism. The nineteenth century gentleman's code, as interpreted through American eyes, envisioned men whose moral probity was unquestioned, whose courage unchallenged, whose stoicism, endurance, and strength understood. Generous, heroic, the individual 
proved his right to adulation by his extraordinary feats, his capacity to perform beyond the abilities of ordinary men. He stood distinct from society and yet was an important element of it, and his success was his guarantee of personal bliss. Perhaps, as Mark Twain suggested, this concept came from the fevered writings of Sir walter scott, perhaps out of the manners and morals of the Victorian era, but, whatever its origins, the idea's influence cannot be doubted. The hero of innumerable Hollywood genre films embodied the same romantic characteristics, and society, through its emphasis on success, has always condoned and encouraged such qualities. Gifted achievers in sports, politics, and business were lauded as long as they maintained the external facade of a chivalrous gentleman.

Butch and Sundance, no matter how far they have drifted from the original model, still believe in and are motivated by the doctrine of individualism. They become criminals because it gives them the freedom to be distinct individuals and the opportunity to gain material wealth. The money allows them to play at and indulge in the role of the gentleman, and they find a camaraderie and a celebrated status that the more conventional figures, such as the marshall, do not. Not only do they enact the role of the individual hero, but they think perpetually in terms of it. Butch talks of joining up and fighting in the SpanishAmerican war. "We could be heroes," he says, envisioning in Boy Scout fashion a career where courage and gallantry 
would result in homage and reward. Such actions and remarks, while typically romantic, reveal an overwhelming naivete, a misunderstanding of society in general and the war in particular. Dominated by their all-consuming belief in the doctrine of individuality, the outlaws can conceive of no other course of action than their present one; they persist in the same routines even as the world collapses around them. They fail to see that the concept of individuality is a myth. Society may encourage personal endeavor, but it suppresses any unfettered individuality. The outlaws' reliance on crime to fulfill the myth is evidence that society provides no opportunities for the romantic spirits it fosters. Nor can they see that the structured technological society has resources beyond their strengths. Their fate is obvious, but they, unable to conceive of any alternatives to their lives, maintain the old ceremonies until the end. Reggie Dunlop and Waldo Pepper are also enthralled by the idea of success. They believe, and their appeal as characters suggests that the audience believes, that success brings concomitant material and spiritual happiness. The homage enjoyed by the successful beckons them, and each in his own way wishes to attain some goal that will seemingly relieve his feelings of inadequacy or dissatisfaction. Such a desire seems second nature in a culture which almost indiscriminately lauds those who have achieved. Stories of spartan denial and dedication are part of the American mythology, and social institutions--religious, civic, and 
educational--constantly urge such striving for perfection. Both men are believers in the doctrine. For Waldo, happiness can only come when he can claim the title of "the best pilot in the world." For Reggie Dunlop, success means the championship and some apochryphally beautiful existence with a loving wife and adoring fans. This dream world, similar to the one fantasized by the moronic sportswriter and the broadcaster, captures Reggie, despite all his intelligence. For both men, the goal is worth any sacrifice. Waldo gives up a relationship with Maudie and any real social contact with people to pursue this elusive dream. Reggie gives up his wife, abuses the emotions of his players, and insensitively uses Lily Braden for his own ends--all for an unrealizable success. The two are so obsessed that they cannot see the emptiness of their own lives and the pain that they cause others.

Billy Pilgrim is the most typically American of Hill's heroes, for he ardently believes in the supremacy of the family, the fundamentally strong and beautiful unit whose enshrinement in the innumerable films reflects the cultural belief in its importance. The films of John Ford, for example, always posit the family as the locus of moral force and cultural strength. Billy accepts this belief, and Slaughterhouse-Five details his search for a family, first with Edgar Derby, then with Val, and finally with Montana. But the film also shows that the "families" are models of impotency (with Derby) and spiritual bankruptcy. Billy's 
willingness to disregard evidence to that effect is a measure of his blind devotion to the ideal, and an explanation of his persistent unhappiness. Since he cannot conceive of any alternative to the family, he suffers painfully with Val, Barbara, and Robert. Billy cannot escape his pain, and the triumph on Tralfamadore shows not so much the traditional strength of the family, but rather that the perfect family exists only in a fantasy, unattainable in our modern world.

At first glance, the con men heroes of The Sting seem atypical, but nonetheless their situation is generally analogous to that of other Hill protagonists. The difference is that only one character, Johnny Hooker, has anything approaching a conventional belief. The younger man believes in equal justice for all. Success, such as his and Luther's, should be a proof of one's skill, intelligence, and manipulative ability; a mark of distinction in a particular trade. It should not be reached, as it is by Lonnegan, through cheating and murder. In order to revenge Luther, and, in effect, assert that all are subject to the same laws and rules, Hooker sets out to humiliate Lonnegan. He becomes an avenging angel, a guarantor of the equality and justice we all hold dear, who defeats the forces of Lonnegan and Lt. Snyder. But curiously his success is not brought about by a reliance on traditional beliefs and emotions; rather it comes through the manipulative skill and miraculous foresight of Gondorff, who is indifferent to revenge and justice. 
Characters so dominated by a concept lose their individuality; they play the role society expects and repress natural feelings in order to maintain a particular image. The outlaws become courteous, chivalrous, and gallant despite the incongruity of their profession with such virtues, and maintain this facade even in times of danger. When they retrieve the money from the Bolivian bandits, they do so because the gentlemanly code demands that they honor their commitment to Percy Gariss, not because they enjoy shooting people or are after the money. Common sense would dictate that they avoid such danger, but they act as they feel they should act, not as the situation would seem to demand. Waldo Pepper is also more posture than person. His fabricated Kessler story is repeated not out of vanity, but out of Waldo's desperate need to fulfill the outward requirements of the individual hero role. He needs proof of his greatness, and manufactures it when circumstances deny him the opportunity to demonstrate his qualifications. The final battle is a costumed sequence, and this fact only underscores the point that waldo plays a role that he finds satisfying. Reggie Dunlop also plays various roles for different people, manipulating them for his own ends. When he drops these assumed masks, he reveals another, more consistent persona. He plays the confident hero for his wife, projecting dreams of imminent success that contrast with the depressing bleakness of his situation. He plays a macho jock for Lily Braden, apparently because he thinks 
it appropriate for a sports hero, and consequently he never moves past crudities with her. She exists only as a conquest, not as a person. Billy Pilgrim so desperately believes in the efficacy of the American family that he goes through the motions of the traditional father role even though his family is a hopeless shambles. Taking a cue from Edgar Derby, Billy, as a good father, eternally praises and supports all that goes on in his family. For example, he tells his Green Beret son that he is proud of him, even though Robert's metamorphosis causes Billy much more pain than pleasure. He defines himself through the father role and exists as a complex of predetermined responses, not as a person. The characters in The Sting adopt an endless series of personas to achieve their con of Lonnegan. They seldom drop the mask, not even for each other, for they have consciously realized what the other Hill characters intuitively know: that it is necessary to meet external requirements in order to meet goals. But the result is still the same: the personality becomes submerged beneath the roles.

Once the difference in character and motivation are seen, the dynamics of Hill's counter story become clearer. As noted earlier, the characters begin as adherents of conventional American beliefs and move, because of their fidelity to those beliefs, to ambiguous resolutions of their problems. Such a filmic structure suggests the inadequacy of conventional views, for they cannot account for 
the changed, occasionally insensitive, sometimes threatening world the characters encounter. The conventional morality, accepted so unthinkingly, is shown to be spiritually bankrupt; the roles it prescribes for individuals are now irrelevant, and it has no reserve resources to sustain its adherents.

Hill's films, then, juxtapose two understandings of the world. On the one hand there are the familiar genre narratives with their conventional metaphysics. The extraordinary success of his films indicates that the genre conventions have maintained their potency. The audience still finds American vitality, ingenuity, and skill attractive, and sees the qualities as tools that enable one to deal with the world. The characters seem familiar heroes, models whom we can safely emulate. But the films also show a world where conventional morality is false and inaccurate, hindering rather than helping the individual deal with the world. Characters who accept the fraudulent conventions dissipate their strengths in pursuit of illusory goals. Integrity, loyalty, skill, and courage are wasted in service to outworn ideals, and the individual, trapped by a system of unrealistic beliefs, is doomed to slow disintegration.

The two narratives, seen together, yield more than the naive optimism of the genre story or the cynicism of the genre variations. The second narrative reveals an ugly side of the first, forcing us to question conventional assumptions often taken for granted. We are asked to see that the frame 
of reference, the genre conventions, is no longer valid, and that a more complex understanding of the world must be arrived at.

Thus the films usually end on a negative note, showing the disparity between the ideal (conventional assumptions) and the depressing reality in which individualism is impossible and characters are doomed by antiquated cultural beliefs. The films can be seen solely as a negative criticism of the culture for they do not suggest an alternative to the traditional understanding of the world. Not one Hill character comes to terms with his problems or discovers any potential solutions. But it is also possible to see the films as implicitly asserting the need for a new independence. The shock of recognition, the realization that Hill's criticisms are correct, may motivate some viewers to action. Instead of blindly accepting the dictates of others, the individual, in order to avoid the fate of Hill's characters, must learn to see with his own eyes, rely on his own judgments, and to be willing to change. The films describe a problem to induce a response, but do not present any solutions.

$$
* * * * * *
$$

The study that follows examines in detail Hill's last four major films, up to but not including slapshot, in an attempt to substantiate the general contentions put forth here. Each analysis tries to show how these ideas are 
developed in the individual films and to describe the various forms taken by this continuing exploration of the American culture.

\section{NOTES}

I See Gerald Mast, A Short History of the Movies, 2nd edition (Indianapolis, 1976), pp. 388, 401-02.

Also, James Monaco, How to Read a Film (New York, 1977), PP. 261-63.

2 See James Roy MacBean, Film and Revolution (Blooming-

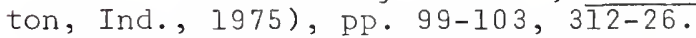

3 As quoted by Robin Wood, "Realism and Revolution," Film Comment, May-June 1977, pp. 17-23.

4 Mast, pp. 264-65, outlines the conventional morality that ruled Hollywood for thirty years. "In 1934, Joseph Breen went to work for the Motion Picture Producers and Distributors of Anerica; Breen's special responsibility for the Hays Office was to serve as official arbiter of movie morality. Breen, a Catholic layman, was pushed into the office by the newly formed Catholic Legion of Decency, which advised the faithful to avoid those films that wereobjectionable either as a whole or in part. Breen published and enforced a formal moral code to keep the films from being objectionable. Movies were to avoid brutality (by gangsters and especially the police), they were to avoid depicting any kind of sexual promiscuity (unwedded, extramarital, or perverted), and they were to avoid making any illegal or immoral life seem either possible or pleasant. . . . The Breen code made marriage more a sacred institution than a sexual one; the bedroom (with obligatory twin beds) became more ornate and holy than a cathedral." (Italics added.)

Robert Sklar, Movie-Made America (New York, 1975), points out that "not only did the movies amuse and entertain the nation through its most severe economic and social disorder, holding it together by their capacity to create unifying myths and dreams, but movie culture in the 1930's became a dominant culture for many Americans, providing new values and social ideals to replace shattered old traditions" (p. 161). Sklar claims that the Production Code of 1930, written by two Catholics, Martin I. Quigley and Daniel A. Lord, operated in the following manner. "The 
code at least faced up to a fact which previous moral regulators had cloaked in ambiguity: without sex and crime pictures, there wouldn't be enough patrons to sustain a movie business. Granting this, Quigley and Father Lord sought to devise a formula that would keep sex and crime pictures within moral bounds. Their solution allowed for a fairly wide leeway in depicting behavior considered immoral by traditional standards--adultery or murder, for example--so long as some element of 'good' in the story balanced what the code defined as evil. This was the formula of 'compensating moral value': if 'bad' acts are committed, they must be counteracted by punishment and retribution, or reform and regeneration, of the sinful one. 'Evil and good are never to be confused throughout the presentation,' the code said. The guilty must be punished; the audience must not be allowed to sympathize with crime or sin.

"The code went on to prohibit a vast range of human expression and experience--homosexuality, which it described as a 'sex perversion,' interracial sex, abortion, incest, drugs, most forms of profanity . . and scores of words defined as vulgar" (p. 174).

5 Monaco, p. 262.

6 Leo Braudy, The World in a Frame (Garden City, N.Y., 1976), p. 112 .
7
Braudy, p. 108 .
8 Braudy, p. 110 .
9 Braudy, p. 110. 
CHAPTER II

BUTCH CASSIDY AND THE SUNDANCE KID

Butch Cassidy and the Sundance Kid (1969) is Hill's

first cinematic triumph, for it demonstrates that he can intelligently explore and treat themes visually. The film takes a stock situation of the Western genre, the conflict between individuals and an advancing society, and by giving it a new shape fashions a comment on American society. The outlaws' story is as much the failure of romantic individualism as it is the triumph of technological society, for the outlaws' unwavering belief in the supremacy of the individual unwittingly brings them to their end. Instead of the traditional genre view that the individual is the dynamic force that prepares the road for and fosters the growth of society, only to be rejected because his individuality does not fit within the restrictions of civilization, Butch Cassidy shows that individuality has become a limiting, enervating cultural concept that ultimately absorbs rather than liberates the self. The outlaw heroes, we discover, are impotent to change. The mythic west is real to them, and they cling to their romantic, myopic view despite all contrary evidence. They continually act out the role of the heroic individual in order to resolve the increasingly complex problems of 
technological society rather than alter old ideas or test new ones. The conception has become perception; the need to be unrestricted, larger-than-life heroes dominates their minds, and all actions are interpreted according to this concept of self. Trapped by the roles, the outlaws become static and, in a world where flux is the norm, die. In Hill's Western, individualism is not so much out of place as it is outmoded.

Most critics would deny the film this depth. Reviewers found it "an enervated and sophisticated business venture," ${ }^{l}$ and claimed that "Hill and Goldman knew exactly what they were doing--making a very slick movie." ${ }^{2}$ Especially criticized was the alleged lack of moral and artistic clarity. The reviewer from Time found it a mishmash of farce and tragedy, while Stanley Kauffmann and Pauline Kael suggested there was no hint of artistic focus. ${ }^{3}$ some claimed that the film was empty because we could not sympathize with the hollow, criminal characters. Kael found schoolteachers like Etta Place, who did honest work, more attractive than the outlaws, while Henry Hart claimed there was a "Iot of anti-establishmentarian glamorizing of criminals," and "that beneath the kidding is the ideology, and some of the propaganda of today's nihilists." 4 other reviewers criticized it on the ground that it had no feeling, no maturity, and no originality. ${ }^{5}$ Those who did like it found it clever enough, and amusing, but not substantial. Hollis Alpert is typical with his comment that "George Roy 
Hill, following the plain lead of William Goldman's fine screenplay, is all fun and games." 6 No one thought the film a serious work.

All these criticisms seem to make one basic error; they judge the film by some fixed, external standard, not by the standards and boundaries the film creates for itself. Consider the claim that the film is suspect because it lacks a moral center and that, as Hart suggests, conscientious characters like Woodcock are more attractive than the amoral heroes. ${ }^{7}$ This might be true in some external system, but it is certainly not true within the movie. Woodcock, we are made to see, fanatically and foolishly clings to his duties because he covets his job, not because of any abstract values. His tenacity evidences his shallowness, and he deserves to be laughed at. Pauline Kael argues that schoolteachers like Etta were more essential to the settling of the West, and are therefore more attractive than the outlaws and flaw the picture. 8 Perhaps schoolteachers were important to the settling of the West, but the film is not about the advance of civilization. When Etta goes with the outlaws, she goes because they offer a vitality that the town cannot. "All the excitement I've ever known is right here with me," she says at the moment of choice. Etta's perhaps foolish choice is for an unordered world rather than the strait jacket of town life.

The most important rebuttal to the claim of immorality, however, is the outlaws' morality. Like Western heroes 
before them, they have a recognizable, attractive code of values. There is a concept of honor (Sundance's willingness to fight for his honor in the opening scenes) and responsibility (their actions with Percy Gariss). They accord respect to others who can survive in their world, and ask only the same respect in return. And their reprehensible larceny appears attractive only if we ignore its debilitating nature. It would be more productive to focus on the subject that seems to attract both the audience and the director: the tension between the individuals and society. The outlaws' story offered Hill the opportunity to explore this perennially intriguing subject, and criticism should focus on his handling of that, not the details. Butch Cassidy is no more about bankrobbing than Bonnie and Clyde. Most viewers enjoyed the film, unaffected by the critics' concerns, for it is a well-done, entertaining genre story. The outlaws and the posse are representative of two ways of life. The outlaws are clearly the traditional heroic individuals, persons who have declared their separateness from the sometimes entangling and leveling restrictions of society. The posse, physically and symbolically, is the force of the new, impersonal technological society. The physical struggle between the two groups becomes a metaphor for the struggle between two ways of life. The posse's triumph signals the beginning of a new, lessattractive world, a celebration of order at the expense of individuality; the film becomes an elegy to a way of life that has passed. 
The genre story is clearly discernible, for Hill highlights the characters' representational status and the differences between the two groups. Butch and Sundance are presented as larger-than-life heroes, the incarnation of the West and its values. They exist throughout the film as almost legendary characters. The title sequence tells us that "they once ruled the West"; E. H. Harriman, the railroad magnate hires a special posse to hunt them down as the last visible threat to the expanding society; the old sheriff identifies them as the last remnants of a dying race; Sundance's skill with a gun has earned him a largerthan-life identity; and the continual use of close-ups emphasizes their stature in relation to the other, almost anonymous characters in the film. Hill endows these characters with qualities that typify the old West. The outlaws survive and triumph through the use of individual skills. They are forthright, honorable, and courageous, loyally supporting and refusing to take advantage of each other. And, though never explicitly stated, these concepts form a code of values by which they live.

Arrayed against them are the men of the posse, the equally archetypal representatives of the new, impersonal society. Anonymous, mercenary, never clearly seen, attributed nearly superhuman powers by the other characters, they are clearly symbolic of the new order. ${ }^{9}$ The leaders of this world, like the unseen E. H. Harriman, and the source of their power, the indistinct crowd in the town, are equally 
faceless and impersonal. The new citizens, like Woodcock, the payroll guard, live and fight for position in an organization rather than for themselves, and, as the failure of the marshall indicates, are indifferent to words like courage, honor, and responsibility.

Most viewers understandably sympathize with the outlaws, for they embody the qualities we desire and admire. We follow them, and suffer with them, and can find their death sad because we see in their refusal to yield to the new order a gallant, though futile gesture. Butch Cassidy (like The Wild Bunch and The Shootist) celebrates an elemental vitality that has been lost in the transition to technological society.

But in addition, Hill frustrates our stock expectations, creating an ambiguity that prevents identification and encourages a distanced, critical perspective on the outlaws and their actions. Once we move past the stock responses, we see that the story is ironic: The film, in exposing the weaknesses of the genre and its metaphysics, moves us from sympathy with the outlaws to a less emotional understanding of their failure. This is not to say the film parodies the genre, only that it examines it more carefully than is customary. It shows the limitations of unchallenged cultural conventions and implicitly urges a new independence: freedom from the chains of ideas, whether they be as restrictive as those of the advancing technological society, or as lulling, but ultimately false, as those of an older world. 
The ironic perspective results from Hill's disruption of our stock responses, and this occurs from the beginning. The title sequence, a throwaway in many commercial films, here establishes the ambiguity prevalent in the outlaws' world, and forces us to think before committing our sympathies. Purpontedly an old newsreel of the Cassidy gang in action, the sequence shows the outlaws robbing a train and then being foiled by a posse. It not only presages the chase sequence in the center of the film, but is also a cinematic allusion to Edwin S. Porter's The Great Train Robbery, the prototypical western film. The situation is the same in the newsreel and in Porter's film, and even some of the shots are similar (the passengers are lined up and robbed in each; a passenger is shot in the Porter film, a guard in the newsreel) in camera placement and composition. However, in the Porter film and the genre that springs from it, people act out of understandable motives; moral values are clear, and rewards and punishments distributed according to that fixed value system. Thus, we know the gang in The Great Train Robbery deserves punishment because they have, by shooting an unarmed passenger, proven their cowardice and immorality. We cheer when they have been captured or killed and the world set right again. In Hill's sequence, the outlaws appear to be bandit heroes. They shoot the guard only because he tried to obtain unfair advantage, another cowardly action that violates the standard moral code. The audience prepares to respond to them until they are cast as 
villains by the appearance of the posse, who break up the robbery. But the resolution is ambiguous. The posse fails to capture the outlaws; the outlaws fail to complete the robbery; and we are left with an inconclusive puzzle that refuses to be solved by any standard emotional response. The title sequence is a tonal rubric of the film. The ambiguities produced by the variations in genre format serve as the first indication that we are not in cinematically familiar territory.

The opening scenes of the film proper grow out of the title sequence in that they continue to develop the sense of ambiguity found there. These sepia-toned scenes appear to be common commercial fare, introducing us to heroes who are likeable and extraordinarily skilled. Yet, if we look carefully, we find that Hill has controlled the cinematic elements to suffuse the scenes with a non-standard sensibility. In the first shot, the camera follows Butch as he cases a bank and then jokes about the bank's formidable security; the joke works (for most viewers) and the humor that is Butch's hallmark is established. However, the visual elements undercut the ease and humor of the scene. The film opens with a rack through focus from a window to a shot of Butch behind a barred window. The association with jail is unavoidable, even though Butch overturns it by stepping out into the street a moment later. Inside the bank, the prison association continues. As Butch stands in the center of the bank, glancing at the various security paraphernalia, 
Hill cuts from the bolts, doors, and windows, slamming and shutting, to Butch's face, which is gradually becoming darker. The montage effect suggests Butch as the one being enclosed and imprisoned. The sense of foreboding is broken by Butch's joke, but the visual content of the scene remains negative; it creates an ambiguous tension, parallel to that of the title sequence, that retards the affective impulse usually accompanying such scenes.

We are then introduced to the Sundance Kid, a more recognizable Western hero. In the duel of nerves with the card dealer, Sundance demonstrates the self-assurance and extraordinary skill expected, winning an immediate and favorable audience response. The visual and dramatic content, however, conveys additional information that alters our understanding of the traditional scene. The juncture between this and the opening scene is the first hint that there is another dimension. As the guard closes the door on Butch, the camera rests on the black door just long enough for us to hear the latch closing. There is then a direct cut to Sundance's face, a shift that joins the connotations of the first scene to the second. Further, if we note the composition, we find a visual comment on the nature of the outlaws' world. Sundance is framed by the shoulders of the card players, thus rendering him explicit and them anonymous. We see the dealer's face only for a moment, when he learns of Sundance's identity. Such composition suggests something of the anonymous nature of the outlaws' opponents, and in a 
small way prepares the groundwork for the posse. Finally, we have Butch's facetious comment that sundance may be "over the hill." The line becomes funny in light of Sundance's performance, but it also introduces the idea of being overtaken, of failing to survive, that is central to the film.

The first two scenes, then, do more than introduce our heroes. First, the base of one of the film's main themes, the passing of an era, is set in the bank and in Butch's comment. Second, since they are shot in a sepia tone, the scenes induce a nostalgic sense of identification with the past; however, there is a concomitant, though less distinct suggestion that the men and the qualities they represent are extinct. Third, the contrast between the visual element and the dramatic element creates an ambiguity that prevents total identification with the heroes. And fourth, the limitations of the outlaws are outlined for us. As the movie progresses, we discover that the outlaws never go beyond the qualities demonstrated here. They always resolve problems by wit or by skill with a gun; for them, it is an individual encounter in an arena, and they never seem able to grasp larger concepts or issues. The opening shots fully develop them.

The movie now shifts to color, but it still develops, by a process of accretion, the ideas suggested in the sepia scenes. We are shown something attractive or humorous, that draws our sympathies for the outlaws, but which also contains shadings that suggest potential dangers or the limitations 
of the characters. The commercial entertainment takes on an added substance that transforms the stereotypes into characters and the stock plot into a vehicle for exploring ideas. Consider, for example, the sequence which follows them back to their camp. The shots show the magnificent countryside, the harsh, yet promising landscape that is part of the American myth of the West. The dialogue affirms that the struggle is between these two classic Western heroes and the changing society, and it reveals the affable humanity of the characters. The talk of Bolivia demonstrates that the outlaws are searching for another place to live, thus making their move there plausible later, and shows that they have some understanding of their situation.

But on another level the dialogue shows that the outlaws' understanding of their situation is superficial and incomplete, and also that this lack is as important as the confrontation with society. Butch simplistically equates Bolivia with the California of 1849, and this equation indicates that, for Butch, an El Dorado always exists, a dreamland where he can enjoy his present lifestyle. The problem for him is not one of accepting the changes encountered; it is one of finding another pastoral locale in which he can avoid the problems of change. Butch and sundance fear change because they cannot comprehend the consequences of it, and remain adamant in their refusal to change. Their present existence seems benevolently ordered for their own greatest good. Their paradise provides everything, and they have 
ample opportunity to demonstrate their rugged individuality. Simply by taking from others they satisfy their need for pleasure, money, status, and self-sufficiency. And, incredibly, such an effort has been blessed by the peculiar circumstances of the time; their ability to survive and prosper on the frontier has made them heroes. No wonder the past holds such attraction for them.

They seem determined to exist there, as their dialogue indicates. When sundance laughs at the outlandishness of Bolivia, Butch deprecatingly pokes fun at himself. "Boy," he says, "I've got vision; the rest of the world's got bifocals." 10 This ironic comment was meant to show Butch's understanding, but there is another edge to it as well. Butch may josh about his ideas, but when it comes to the acid test he embraces them: He goes to Bolivia and chases his dream. He may sense that his understanding is incomplete, may joke about it, but he will not make an effort to correct it. The attractions of the past exert too great a hold on him. Sundance's laugh and dismissal of the remark with a shrug indicates a similar weakness on his part. He acts only when physically threatened; otherwise he is content to let events, thoughts, and insights pass him by . Unless confronted with something concrete, Sundance, pure response, cannot deal with the world around him. He is limited by his perception of what is important (his honor and his survival), content to let others lead him, and unwilling to question himself or his world. 
The exchange introduces a new dimension to their struggle, for we see that the outlaws are ill-equipped to deal with the advancing society. Their childishly naive understanding of the world is so superficial as to be unacceptable; it seems founded on some vague conceptions of an Edenic past. In traditional films, as Michael Wood points out, there is never any question of the value of individuality, only its place in relation to society. ${ }^{11}$ Here, the individuality associated with the outlaws is problematical; it seems incapable of dealing with the world, and we are forced to question its potency and value. Central to this questioning is the problem of vision, to use the language of Butch's metaphor. We realize that their survival depends on the clarity with which they see, and, if this scene is an indication, their perspicuity is sadly lacking. As the film progresses, we find them continually limited by their inability to see beyond the outlines of a romantic myth, and the question of their perceptual acuity becomes as much a part of the film as does the elegy to their lost way of life. The scenes with Harvey and the first train robbery well illustrate the importance of perception. Most viewers see them as entertaining incidents, laughing as Butch outwits Harvey and Woodcock, and strengthening its identification with the bandits. But the scenes also reveal the increasing pressure on the outlaws' world: internally, from the members of the gang, and externally, from the new organization man. Woodcock delays the robbery for only a few 
seconds, but his motive, love of place in an organization, is a veiled warning to the outlaws. And, of course, the scenes show the outlaws are unable to comprehend the danger to their idyllic world.

This inability is evidenced in the scene with Harvey, in which Butch defeats the clod with some fast talk and a kick to the groin. It is generally humorous, but one shot suggests another response. Hill disturbs our perception of the scene, disrupting our stock response, by having a "screen" of dust flow between the characters and the camera; he asks, in effect, that we exert ourselves in order to see the scene. We are given a medium close-up of Butch's face as he spins a line about needing to spend more time in town. As he speaks, a cloud of dust passes in front of him, obscuring Harvey from him and him from us--a visual metaphor for Butch's clouded vision. He cannot see that Harvey represents something beyond mere physical danger, nor that circumstances are forcing him to spend more time in town. To him it is only a challenge, another opportunity to prove his individual ability to survive. He cannot or will not see events as anything other than a continuing chapter in an endless fairy tale. 12

The scene with Woodcock serves as a similar reminder. Woodcock's inept bungling induces laughter as the genre hero encounters the buffoon. But once we reflect on the scene, the stock response again proves inadequate. Woodcook foreshadows something dangerous. His willingness to die for an 
organization is representative of the lack of individuality and the desire for anonymity that will doom the outlaws. Butch, with his comment that "all that matters is that we come out ahead," reduces the situation to an I-win-you-lose formula; he deals with the present, and cannot move beyond the immediate. To most in the audience he remains attractive, but as he stands in the swirling smoke (perhaps accidental, but perhaps seized upon by Hill for use as a metaphor), he remains undeniably limited.

The town sequence that follows emphasizes the same point. On the one hand the scene is funny, with the cuts between the fatuous marshall and the relaxing outlaws; on the other hand it indicates the serious dangers that must be faced and the outlaws' non-comprehension of them. The subtle shift in attitude indicated by the marshall's failure is frightening. He cannot raise a posse with appeals to duty, individual responsibility, or self-respect because the people in the town find these ideas meaningless. The apathetic crowd is representative of the new sheep, people who retreat into anonymity and the safety of the group. They have relinquished their individuality for the guarantee of safety, and contrast sharply with the outlaws, who are still willing to fight for their honor. The threat such an attitude represents, the massed power of such blank mindless force, though minimized by laughter, should not be ignored.

The second threat is the bicycle salesman, with his machine "that won't do much--only change the course of your 
lives." Butch indulges childishly in the novelty of the bike and does not see that the new technology is altering the west. The thind element is less obvious. The dialogue between the two men reveals a naivete, an unthinking belief in nineteenth century romanticism, that will always have difficulty dealing with the world. Butch suggests joining up and fighting in the Spanish-American war; "We could be heroes," he says. The comment evidences such a simplistic picture of war and the world that even sundance reacts; he burst the bubble by saying Butch is too old. Butch is angered, so Sundance backs off and restores peace. Butch cannot accept criticism because it implies error and is an implicit challenge to the perfection of his daydream world. Sundance cannot be bothered with anything other than his immediate situation; he seems to hope indifference will dissipate his problems. Their tolerance for each other keeps the relationship smooth, but it should not prevent us from seeing the extent of their limitations.

Next comes the bike riding scene, carefree and joyous, with its bright colors, soft focus photography, and lyric music. Yet even in the midst of it, detail indicates that the outlaws will not be able to maintain this bliss. As Butch and Etta roll under the trees, Etta picks off an apple, takes a bite, and hands it to Butch. Associations with the Garden of Eden and a fall from paradise come to mind, particularly when we consider that the happiness stressed through color, music, and photography is taking 
place aboard a bike, the symbol of a new era. The means of destruction has already entered the paradise. In addition, another "screen," this time of blossoms, obtrudes and slightly obscures our vision during the last exchange of dialogue. The "screen" suggests again that the action needs more than a superficial glance to be understood. Butch tells Etta that a shortage of money necessitates another robbery, a problem Etta suggests is caused by Butch's foolish, spendthrift ways. He shrugs in agreement and moves on through the blossoms, ever unwilling to consider the implications. He cannot "see" the problem because his internal perception is as blurred as the physical.

At this point, the film has developed the outlaws' character, both strengths and weaknesses, and outlined the nature of the forces arranged against them. The film has demonstrated their admirable qualities, inducing almost total identification with them, and thus allowing us to share in their happiness and gaiety. Also, we align ourselves with them in the seemingly clear-cut struggle against the encroaching society. Yet the attractiveness and simplicity covers a more complex situation. The movie dissociates us from the outlaws by constantly reminding us that there is something intrinsically awry with their way of living. The outlaws' continuing inability to comprehend the world around them interferes with our simple emotional response. In addition, not only has each scene contributed to our awareness of their limitations, but the sequence of situations, 
the narrative structure, suggests that their world is slowly disintegrating. They move from less to more threatening situations, a structural progression that parallels and underscores the gradual erosion of their world. By the time of the bicycle sequence, there is a tension that must be resolved, and it is apparently done in the chase sequence. That reaffirms the outlaws' humanity, and gives an old answer to the problem of encroaching society: flight to less developed lands. The trip to New York City and the Bolivian robbery sequence seem the realization of that traditional possibility. But, as always, Hill undercuts their triumph, showing instead that they are only proceeding in the same self-destructive direction. The shootout with the army in Bolivia is simply a substitute for the shootout with the posse, a moment they have been able to delay, not escape. Their struggle at first calls forth the audience's sympathy. As the posse becomes more resolute, the outlaws become more human and accessible, suffering reversals, and becoming tired, dirty, and drawn. Their extraordinary skills fail them, and they escape only by virtue of chance, a quality that heroes rise above. In contrast to their humanity stands the abstract nature of the posse; it seems pure presence, the antithetical force that opposes all outlaws. We first see the engine of their train, shot in low or odd angles to emphasize its size and power, and presented in a montage of parts to point out its impersonality. The posse disgorged from the train takes on these same qualities. Their skill 
and power are evidenced through the quick killing of the two outlaws, and their impersonality through the series of extreme long shots. The camera draws farther and farther away until they become a series of lights, a cloud of dust on the horizon. In some sequences there is only a shot of the landscape, recently traversed by the outlaws, and a sound, something like distant thunder, which suggests the presence of the pursuing force. The outlaws' questions--"Who are those guys?" "Don't they ever quit?" "Why don't they do something different?"--only emphasize the metaphoric nature of the posse. It has become the physical incarnation of the technological society, the threat of death.

But the chase sequence also reveals the fundamental limitations of the characters. The sequence begins with a comic set piece, the second encounter with woodcock, that subtly points out the growing danger and the outlaws' obliviousness to it. There is laughable confusion in the explosion and the chase for money, but in the more formidable safe lies another threatening technological development. The ubiquitous dust cloud is again present as the outlaws remain insensitive to the veiled threat of the safe. After the chase gets underway, the insensitivity seems to increase rather than decrease. This is perhaps clearest in the scene with the old sheriff. They offer to trade their banditry for army commissions, an idea so absurd the sheriff scoffs. "Your times is dead," he tells them. "All you can do is choose where you're going to die." The outlaws, true to 
form, refuse to accept the increasingly obvious judgment, and sheepishly depart. But we cannot ignore the accuracy of that insight, for the action in the rest of the sequence confirms the sheriff's assertion. Butch tries trick after trick, with equal ineffectiveness, but still refuses to believe that his skills will not somehow save him. He cannot grasp the totality of his situation because his mind has rejected the possibility of failure or surrender. In his life and his romantic conceptions, success always follows a great individual effort, and so he retains a blind faith in the certainty of his own triumph. To him the posse is only a more difficult test than his encounters with Harvey and Woodcock. They ultimately escape, but only through a desperation leap that delays, but does not eliminate, a confrontation with the new force. However, they see the escape as some natural extension of their luck. Rather than change, they decide to go to Bolivia. For them, it is still a problem of locale, not one of vision or conception of the world. Etta knows this is self-deception, but our heroes push blindly backward in spite of her.

The second half of the film parallels the first. The outlaws draw our sympathies, but also reveal the same weaknesses that repelled us earlier. We see that they are doomed, and remain victims of their romantic mythology. There are two long entertaining visual sequences that captivate the audience and simultaneously reveal that the weaknesses have not been shed in the transition from America to Bolivia. 
In the city sequence we follow the outlaws from the slowly turning bike wheel, the symbol of the new era, which Butch has rejected, to New York, the center of the new world. The trio is immensely attractive as they toy with turn of the century New York, indulging themselves in its amusements, posturing and posing--children on a holiday. Their attractiveness arises from the fact that they view the 1890's as a fantasy world to be enjoyed, not something to be taken seriously. And the technique of the sequence underscores this fact. The stills, the montage, the lively music, the locations--amusement galleries and public parks--, and the sepia tone all seem to flow together to create a sense of spontaneity and fun that is part of the outlaws' character. But even so, that should not prevent us from seeing that they are incapable of dealing with New York except as a dream world. They cannot survive here, and must move backwards, as the right to left motion of the train indicates, to the pastoral locale of Bolivia. 13

The bank robbery sequence in Bolivia is another superb example of Hill's ability to combine concrete narrative detail and abstract thematic statement into entertaining fare. We follow the outlaws as they progress from bumbling amateurs and regain their status as first-class robbers. In a few minutes of film time, they gain the same notoriety and success that were the subject of the first half of the film. Other shots, though, remind us that the outlaws, despite all their success, are still on the same treadmill. 
In one robbery sequence the camera focuses not on their cleverness, but on a bound bankguard, and follows his gaze as he looks from the outlaws to a poster for "Bandidos Yanquis." Their pastoral locale becomes another arena for a confrontation between the outlaws and the forces of the society. Once again they have inadvertently created a potentially destructive situation. Another shot shows the outlaws escaping from the soldiens with a variation of the "Sweetface" ruse, the same trick that failed them in their chase with the posse. They have not moved forward; simply fallen back into their old patterns, complete with the same tired ruses that will ultimately fail again. When the sequence finishes, the intimation is confirmed. Etta and the outlaws are forced from a luxury dinner by the sighting of a white skimmer, a trademark of the man who led the posse. This is a final revelation of their doom. The audience knows that it is implausible, but the outlaws, haunted by a selfprojected fear, are trapped into the same old response of flight. We realize now that they are endlessly fated to play out the same scenario, always the victims of their own projections.

They decide to go straight, but their romantic conceptions make it a futile gesture. They still must fulfill the requirements of the code, only they discover it now to be an empty and unsatisfying experience. Instead of metamorphosis, they cloak the old self with a new costume, that of payroll guards for Percy Gariss. When he gets shot, they 
are put in the novel position of avenging a crime, for they feel they must honor their commitment to him. This leads them to a shootout with the bandits in which Butch reaches perhaps the nadir of his career when for the first time he is forced to shoot another man. The slow motion filming emphasizes the violence, reflecting Butch's horror at the killings. The finality of his descent is then underscored as a cloud of dust moves in front of his face and a sound, like distant thunder, is faintly heard. Butch still cannot see the significance of his experiences; he remains haunted by the posse, his avenues of escape slowly disappearing. Etta's departure soon after fulfills her prophecy that she would not watch them die.

The process of disintegration is quickly concluded. We see the outlaws reduced to jungle work, bickering with each other, and eating cheap meals in dirty towns. They have reached the end of their journey, and the shootout is a logical conclusion to the film. In that final battle, we see the essential paradox of their lives. Their strengths and attractive qualities, derived from the code of the hero, prevent them from clearly seeing their situation or doing anything about their occasionally gleared insights. Even though they are doomed, they play the role, gallantly fulfilling the gentleman's code by maintaining a brave and indifferent facade in the midst of danger. They talk again, in the same half-mock, half-serious tone with which they talked of Bolivia, of new adventures. But the code, which 
has no applicability except perhaps in moments of danger, prevents them from ever going beyond that half-mocking tone. They go to their deaths, misinterpreting their immediate situation and oblivious to the larger context of their lives. The film ends as an indictment of the American concepts of heroism and individuality. The disappearance of the individual, the film suggests, was caused as much by the nature of the idea as by the advancing society. The American West, so often associated with individualism, serves as the focal point of this study. Hill introduces figures who seem archetypal incarnations of the Western hero: courageous, gallant, talented, affable, and free from restraint, creators and masters of their own world. But he also shows the flaw in this ideal. In achieving their individuality, the characters have sacrificed the ability to respond and grow with the changing situations. The image has trapped the man. They feel they must play a hero's role and perform in certain ways, or else lose their feeling of worth. Even though the role no longer accords with reality, they cling to it, for they can conceive of no alternatives. In accepting the anachronistic concept of individuality, Butch and sundance have cut themselves off from the flow of life. Their inability to comprehend anything except in terms of this individual mystique makes them easy victims of technological society.

The perceptive viewer can see that American individualism, in addition to its immense attractiveness, has an 
inherent weakness, a preoccupation with the concerns of role that prevents growth. Somehow, the film suggests, we must enlarge our field of vision so that that pursuit of dreams does not become a selfish, self-limiting, self-defeating struggle.

Butch Cassidy is Hill's first film to go beyond genre limitations, using the familiar material as part of a new creation, an incisive examination of the culture's fundamental assumptions. It marks a new stage of growth and maturity in Hill's career, commercially and artistically, one that continues in his next film, Slaughterhouse-Five.

\section{Notes}

I Pauline Kael, "The Bottom of the Pit," New Yorker, 45, 27 September 1969, p. 128.

2 Vincent Canby, rev. of Butch Cassidy and the Sundance Kid, The New York Times, 25 September 1969, p. 54, col. I.

3 See "Double Vision," Time, 94, 26 September 1969, p. 94. Also Kael, p. 128, tells us that Hill "doesn't really seem to have the style for anything, yet there is a basic decency and intelligence in his work." She also suggests, p. 127, that the film is "a glorified vacuum." Stanley Kauffmann, "On Film," New Republic, 161, 26 October 1969 , p. 32, tells us that the film is "unfocused and unrealized." Roland Gelatt, "The Old Refrain," Saturday Review, 20 September 1969 , p. 30, suggests that the film, with its modernisms, is uneven and unsuccessful.

4 Kael, p. 128. Also, Henry Hart, rev. of Butch Cassidy and the sundance Kid, Films in Review, 20, No. 8, p. 510.

5 Kael, pp. 128-29, says that "after watching a put-on rape and Conrad Hall's 'Elvira Madigan' lyric interlude... . I began to long for something simple and halfway felt. If you can't manage genuine sophistication, you may be better off simple." Kauffmann, P. 32, says that "Hill's direction, 
like the writing, is imitative of everything that's 'in.'" Canby, p. 54, claims that the outlaws" "decline and fall was the sort of alternately absurd and dreamy saga that might have been fantasized by Truffaut's Jules and Jim and Catherine--before they grew up." John Simon, Movies into Film (New York, 1971), pp. 177-78, finds the film filled with a "plethora of supposedly stylish devices," imitative of Bonnie and Clyde, and an attempt to be "very attentive to period flavor, and wildly 'now." He claims that "Hill's direction, like Goldman's scenario and Hall's cinematography, is too adorably and calculatedly puckish, as if the film had been made by a bunch of corrupt koalas."

6 Hollis Alpert, "Variations on a Western Theme," Saturday Review, 27 September 1969, p. 39.

7 Hart, P. 510.

8

Kael, P. 128 .

9 The posse consists of hired guns instead of the traditional group of aroused citizens.

I0 All quotes are from the films; any italics have been added.

11 Michael Wood, America in the Movies (New York, 1975), pp. 24-51.

12 In the documentary film, The Making of Butch Cassidy and the Sundance Kid, Hill remarks that he experimented with foilage masks to screen the actors' faces. The experiment was rejected because it was too awkward, but the remark shows that Hill's use of a screen would not be accidental.

13 The outlaws' inability to cope with the new world is also illustrated by Sundance's remark that he is from New Jersey. He left the East because he could not find a compatible life there. 
CHAPTER III

\section{SLAUGHTERHOUSE-FIVE}

Billy Pilgrim, the American Dreamer in Hill's Slaughterhouse-Five (1972), searches for the security and happiness that participation in the dream supposedly provides. He fails to find it, however, in a world that contains the horror of Dresden and the stultifying vapidness of Ilium, and instead retreats to the paradise of Tralfamadore. Life there is eminently satisfying to him, for it seems at last an affirmation of the American Dream. On Tralfamadore, respect, kindness, courtesy, and love help relieve suffering and create the spiritual happiness that serves as an alternative to the shallow, materialistic world of Ilium.

Slaughterhouse-Five, then, seems another statement of conventional wisdom in its insistence that a return to spiritual values brings happiness. The film follows Billy Pilgrim, the archetypal American, born on the Fourth of July, as he attempts to bring his search for happiness to a successful end. It follows him as he accepts the ideals of Edgar Derby, the incarnation of small town American goodness, and then discovers the inadequacy of Derby's idealism in a harsh, modern world. The film follows Billy as he converts to the ideals of the American material dream, the 
equation of material success with happiness. But, as the film humorously and satirically points out, that life is a false and shallow existence, hardly worth the having. It follows him as he finally escapes to Tralfamadore, where the timeless spiritual values of family and basic decency serve as a base upon which to build happiness.

So constructed, the film seems a satire of modern American life and an affimmation of traditional American values. It rips apart one American dream, that of material success, and asserts the supremacy of another, the ascendancy of basic spiritual and family values. Most of the critics who liked the film agreed that this affirmation of traditional values was one of the film's enjoyable attributes. I But the film is more properly a savage attack on the spiritual poverty of the American culture. While presenting what seems a familiar story, Hill adds and alters elements to jolt the viewer from a comfortable, conventional perception of the story and character. Hill creates a discrepancy between what we see and what we expected to see, encouraging the perceptive viewer to probe the American myth of success. In so doing, we discover that Billy Pilgrim is transformed from the stereotype of a bumbling, good-natured, common man into a complex character troubled by his painful memories of the war. His war experiences--his confrontation with suffering, his recognition (through the death of Derby) of his own mortality, and the responsibility that he, as an American, must somehow share for the senseless slaughter 
of the war--have become obdurate problems which resist his efforts at resolution. Uncharacteristically, the American culture which he so unwaveringly embraces fails to help him; its values provide no satisfactory solution, and Billy turns instead to a world of fantasy. Hill shows Billy as a dreamer whose longings for security and happiness, seemingly unattainable in Dresden or Ilium, drive him to create Tralfamadore, a world of the mind to which he can retreat. His need to resort to fantasy become a measure of his and the culture's limitations, and the configuration of the fantasy (Tralfamadore is basically America) suggests something of the culture's destitution. The values of family and virtue are not so much affirmed as attacked, forcing us tore-examine those tenets which seem central to the American ethic.

Initially, Hill establishes Billy Pilgrim as a sympathetic and readily identifiable American character: the naif. Billy is the classic rube who makes good, attaining a success others thought beyond him or willfully tried to deny him. ${ }^{2}$ He has many Iimitations, a condition with which we can all identify, but none that interferes with his attainment of happiness. His career becomes a proof that the common man, despite the lack of extraordinary intelligence, physical prowess, or heroic character can eventually triumph. The film develops Billy's character in traditional style, and the story rarely departs from his experiences. We begin witnessing events from his perspective, the camera inside the house, following the screeching daughter. The 
composition and staging always focus on Billy; we follow him when he leaves a group and focus on him within a group. Several scenes converge upon or expand from Billy, the camera moving in to or out from him for a close-up, suggesting that he is the center of the filmic universe. For example, Hill cuts from the collapsed Billy in the British p.o.w. barracks to the sleeping Billy on the lawn in Ilium, or from Billy on Tralfamadore whispering to Montana to Billy in the foxhole whispering similar words.

But this central position alone does not warrant our sympathy; Billy earns that because of his character. In his relationship with Montana, for example, Billy is strong, courteous, and gentlemanly. In his indifference to tangible wealth, he seems a spiritual pilgrim, someone searching for permanent values to oppose to the temporary material values of Ilium. His patience with and consideration for Val and Robert, his good nature, and his child-like innocence all reinforce his saintliness.

Comparison with other characters heightens these qualities. Lazzaro is a vicious, cowardly psychopath whose inhumanity stands in marked contrast to Billy's endless gentleness. The arrogance and posturing of Lazzaro, such as the nonsense about the Detroit Tigers, are constantly undercut by Billy's naivete. And Lazzaro's lack of honor, evidenced in the scene with Campbell, also helps push our sympathy toward Billy. Lazzaro, although a caricature, highlights Billy's character. The Pilgrim family provides another 
counterpart. Val is an exaggeration of the bourgeois housewife obsessed with status climbing and the outward trappings of success. Her constant squealing over Cadillacs and diamonds and her sexless attire increase our sympathies for Billy, while the puritanical self-righteousness of Val and Barbara and Robert's truculency make Billy seem intelligent, moderate, and human.

Finally, Billy draws our sympathy because he suffers unfairly at the hands of an incomprehensible fate. He seems unjustly put upon by his war experiences and, to a lesser extent, his family. Though the horror of the firebombing of Dresden can only be minimally suggested on camera, we sense that its effect was devastating. The grotesquerie of mere survival, of the search for and the burning of bodies, and the senseless death of Derby all contribute to a nightmare that haunts Billy after the war's close. Billy also suffers in Ilium, although on a more limited scale. He is surrounded by people who have no conception of what he has endured. His mother and $\mathrm{Mr}$. Rosewater talk of Dresden in an insincere garden-party tone; the doctor who administers the shock treatments talks as if giving a lecture: "Billy was in Dresden during the war. . and it's only natural to assume it's had some effect on him." At home, life is equally painful. In the wedding night sequence, Val crawls all over the inert Billy, smothering him with kisses, cooing the romantic and moral conventions of the forties. "I'm so glad we waited. . you've had experiences in the war, 
but I understand. . ." For her, married life is a succession of salads and shortcakes; the children something to show off to her girlfriends; the gifts of diamonds and cars, and Billy's success, so many badges of status; and Billy some kind of addendum that fills out a perfect life. She is incapable of seeing that Billy is unhappy in his own home, a stranger whose only friend is his dog; she cheerfully converts his painful wartime experiences into conversation topics, insensitively driving Billy away.

If Billy's character is recongizable and sympathetic, his actions are also familiar. Billy is a searcher (as the name Pilgrim implies) for those spiritual values which will make life worthwhile and happiness possible. At first he seeks to integrate himself into society; later, he seeks to integrate his war experiences into his civilian life, to free himself from the memories of suffering and death. others in the war are not so troubled. Lazzaro and Weary are certain of who they are ("We're Americans," Weary confidently explains); the British major in the p.o.w. camp has his litany of bowel evacuation and teeth brushing to sustain himself; and Campbell is spurred by his hatred of communism, his conviction that the world would be right should be eliminate Russians and Jews. But Billy is different. He has experienced firsthand and cannot forget the brutality of the senseless human suffering at Dresden. He can never escape the consciousness that meaningless pain was inflicted on human beings by other human beings. In 
this way, he is analogous to his hospital companion, Rumford. When Rumford is confronted with a living reminder of the human pain and suffering at Dresden, he cannot rationalize it and lapses into shallow, bombastic political crudities. Billy, who continually confronts the spectre of suffering in his own memories, cannot afford the luxury of mere speechmaking. He must find another means of understanding his experiences. He makes two wrongheaded lurches toward this goal before he eventually sets himself in the right direction. The audience suffers with Billy as he first follows the Boy Scout idealism of Edgar Derby and then the materialism of middle America, and then identifies with Billy when he embraces Tralfamadore.

Billy's search is established at the beginning of the film. The long shots of him stumbling through the snow stress his isolation and emphasize his insignificance. He seems lost in the infinite white expanse. His experiences in the foxhole reveal that his isolation and dislocation are spiritual as well as physical. Billy does not fit in with the cartoon strip world of Lazzaro, which is filled with forties' war movie clichés such as baseball players, dogtags, love of guns, and fanatical courage. Equally obvious is Billy's sense of the difference. "You guys go on without me," he constantly tells them, apparently used to the chasm between himself and his fellow soldiers. The difference is further manifested in Billy's malleability. People continually single him out, sensing that he has not 
yet solidified his character, and is therefore manipulable. Lazzaro feeds on Billy's weakness, knowing that he at least will be intimidated by his vicious rhetoric. The German soldiers single Billy out for the woman's coat, and the German photographer finds Billy the perfect conquered American. The British P.o.w. senses that Billy needs special knowledge to understand his role in the war and spares no effort to enlighten him. The whores in the window spot Billy's naivete, and the children of Dresden find him a kind of magical creature for their games. And Wild Bob, who can get no one else to listen to him, manages to transform Billy into the best shot in the legendary 451 st. For his part, Billy happily complies with the impositions, smiling sheepishly whenever he pleases anyone, regardless of uniform or intentions. He has no identity, and consequently revels in whatever role is offered him, doing almost anything for a little acceptance. As his attire, the woman's coat and the silver boots, indicates, not even the armies of Germany and America can mold him; as his actions indicate, this special status would gladly be traded for admission into society.

Billy's search for acceptance, though, is not haphazard. As the scenes with Derby demonstrate, he has a definite goal in mind. For Billy, happiness seems to consist of the mythical small town values that Derby symbolizes. Derby, the honest, decent, hardworking, upstanding, productive member of the community, is fiercely patriotic, 
devoted to his family, and an exemplar of sexual restraint and fidelity. He sincerely believes and acts on the values and ideals upon which America was founded. For example, he constantly points out the German violations of the Geneva convention, confident that they only need a friendly reminder to correct them; and he endlessly supports anything American. When Lazzaro gets out of line, Derby tells him that "we Americans have got to stick together." When Billy reveals his disappointment in his henpecked father, Derby tells him to "never sell him short."

Billy obviously idolizes the man and his ideals. The time with Derby is the only part of Billy's life in which he demonstrates any enthusiasm, for in Derby he has found a father to guide him. Derby (whom Lazzaro calls "Pop") leads Billy's thoughts and actions, by example--during the election of the p.o.w. leader--or by rhetoric--as in the confrontation with Campbell. He also protects Billy from the marauding Lazzaro. There is a spiritual bond established in the scenes between the two men. Billy calls Derby the "greatest father in the world" because of the open affection Derby displays for his son. When Billy explains he became an optometrist to help others, Derby applauds the sentiment: "That's self-determination and free enterprise backing itself up all the way! That's why we're here in Europe fighting Hitler!" When Derby is elected to lead the p.o.w.'s, Billy is his only supporter. The cross cuts between Derby's election and Billy's election to the Lions Club, as well as 
the similarity of their speeches, emphasize the relationship between the two men.

And so Billy joins Derby in a celebration of the American virtues. But, the film suggests, such confidence has been misplaced. It is not that the old virtues are wrong, only wrongheaded; they no longer apply in the harsh, modern world. Their time was in the distant mythical America of small towns and enlightened leaders. This inadequacy is emphasized in the film by Derby's actions. For all his virtues, Derby is a curiously impotent father figure, ineffective in his ministrations to his children, and one who ultimately dies a victim of his own romantic conceptions. Nobody really listens to him, not Lazzaro, not the German commandant, nor the young German guard. Guided by archaic romantic ideals, Derby cannot fathom the nature of the American character. He cannot see, for example, that the savage energy of Lazzaro is just as much a part of America as the familial paradise from which he springs. Hill's camera, though, makes the point for the audience. In the election scene, Derby and Billy are foreground, Lazzaro in the rear, the composition of the shot reminding us that there is another dimension to be considered. In the letter scene, in which Derby talks of his love for his son, Lazzaro again lurks in the background, a silent counterpoint to the idealism of Derby and Billy. In addition to misjudging the Germans and Americans, Derby seems incapable of understanding the seriousness of his position. In one scene, for 
example, he and the other prisoners parade down a Dresden street; he and Billy talk, failing to see a corpse hanging in the background. The savagery of war is not visible to them, although the audience perceives it. Derby is forever distracted by the beauty of things, flowers and pieces of Dresden china. Though rare and admirable, this aesthetic sensibility leads to his senseless death.

Billy's simplistic idealism is shattered with Derby's death, and he is forced to seek some new vision, some new way of understanding the world. At first, as the shock treatment scenes make clear, he has difficulty in coping with his painful memories. But stability comes when he marries Val and lives as the archetypal middle-American burgher. Through the creation of a family unit and financial success he apparently hopes to overcome his sense of displacement and uneasiness. Yet his attempt fails. Billy is uncomfortable in Ilium, where his family is a travesty of the "nice" life recounted by Derby. Where Derby and his wife apparently loved and supported each other, Billy and his wife obviously do not. Where Derby and his son earned each other's respect, Billy and his son seem at odds. Robert is a vandal, an antisocial embarrassment, instead of a source of happiness. His metamorphosis into Green Beret and modern Howard Campbell, complete with "fag uniform" and anti-communist rhetoric, only exposes the magnitude of Billy's familial failure. His son falls by the wayside, betraying Billy like Val and Barbara. Uncomfortable 
in the father role, Billy compensates by the overwork that leads to his phenomenal material success and by a giftgiving habit that only highlights the emptiness of his relationships. His plane crash ends this particular segment of his life, revealing to him that transitory material things cannot provide the happiness he seeks. Val's death and Robert's transformation tear away the remaining illusions that Billy has foolishly entertained.

At this low point, Billy is suddenly whisked to Tralfamadore and given an opportunity to create the mythic American world that guaranteed happiness. He wins Montana, and with her begins the family unit he unsuccessfully searched for on Earth. He and she share a love and a joy in their child that Billy never had with Val. As a bonus, Billy is also removed from the sufferings on Earth. Ilium and Dresden are just stations on a time-tripping journey, unpleasant moments that will ultimately be by-passed. The audience, which usually identifies with Billy, applauds his escape to the dome and Montana. Life on Tralfamadore seems an affirmation of the traditional American belief that those of good heart will eventually reap spiritual and emotional rewards.

But, as I also suggested earlier, this interpretation fails to account for the variations in the traditional genre story. Hill directs the broadly sketched characters and familiar plot in such a way that we must question the simple view. Billy is transformed from naif to a spiritually 
enervated sunvivor of Dresden, a dreamer who uses the fantasy world of Tralfamadore as a shield against the suffering witnessed at Dresden. Consequently, Tralfamadore and the mythical American values associated with it become fantastical, its virtues inadequate and inappropriate for modern life. For Billy, Tralfamadore is an alternative to Dresden and Ilium, a familial paradise in which guilt is absolved and death denied. However Hill, by controlling the cinematic elements, denies Tralfamadore's substantiality. Tralfamadore is linked to Billy's mental processes, made a part of his world, not separate from it, and the Tralfamadorian assertions about the nature of the universe are denied by the film's assertions. Tralfamadore can be seen only as an escapist fantasy, a self-created refuge from the world.

The assentions of Billy and those of the Tralfamadorian voice make clear the true nature of the Tralfamadorian vision: on the planet there is no responsibility, suffering, or death. When Billy arrives in the dome, he is informed that there is no such thing as free will. "We've visited 31 inhabited planets," the voice tells him, "and studied reports of a hundred more. Only on earth is there talk of free will." Without free will, of course, there can be no individual responsibility, for actions are then determined by fate or chance. Better yet, Billy discovers, there is no time-everything has always been, is, and will be. Nor is there any pain. The soothing voice tells Billy that "the best way to spend a pleasant jounney is to ignore the bad moments 
and concentrate on the good." Billy responds to this vision, and it has an almost miraculously salutary effect on him. In the final confrontation with his daughter and son-in-law, Billy makes it clear Tralfamadore has rescued him. "I'm not going to commit myself to an institution. If it weren't for Tralfamadore I might have needed an institution." For, as he says, "on Tralfamadore you learn that the world is just a collection of moments all strung together in beautiful random order." He has also learned that "if we're going to survive, it's up to us to concentrate on the good moments and ignore the bad." Billy has found a world which lacks individual responsibility, where suffering can be eliminated, and where death no longer limits. Even without Montana, Tralfamadore is a conventional paradise.

But the film undercuts Tralfamadore, just as it satirized Derby and Ilium. The style, structure, and content reveal that death, suffering, and accountability are integral parts of the universe; any attempt to deny their existence is a willful disregard of the facts, an unwarranted retreat into fantasy. Crucial to Billy's conception of the world is the idea of randomness, of moments strung together in arbitrary order. But the style of the film shows, contrary to his assertion, that all is interconnected. The events of the film are linked associatively, not in random order, suggesting that Billy's journey is internal, a mental exploration of his past and pondering of his future, not a real experience. 
In the opening scene, for example, we go from the loud clicking of the typewriter to the clacking of the tanks, from the rasping sound of the slide into the foxhole back to the typewriter, from thoughts of Montana to Montana, and from a cooing Billy on Tralfamadore to a cooing Billy in the foxhole. The scenes are linked, not disparate. There are also other cuts that emphasize the connection between events. We move from the face in the soupbowl to the face on the lawn, the diamond in Derby's hand to the diamond at the anniversary party, and from the p.o.w. camp shower to the Ilium swimming pool shower. In addition, there are instances where two sequences are joined by a voice over, a technique that creates an even stronger impression of unity. When selected from the p.o.w. Iine by the German photographer, Billy moves freely between his image and voice and that of the American photographer at the dedication of the Pilgrim building. On the operating table, Billy flashes back to Dresden, seeing incidents there, but hearing the respirator and the doctor's voice. Rumford's political tirade supports visuals from the hospital and Dresden, and the Tralfamadorian voice explains the dome and Dresden. After the operation, the Slaughterhouse-Five corridor dissolves into the IIium hospital corridor, another transition device that links rather than separates the two incidents. ${ }^{3}$

Such devices disprove the randomness proclaimed by Billy, for they clearly join separate experiences. The transitions also show that the war is the dominant, formative 
experience in Billy's life, and suggest that we are witnessing an attempt to reconcile the past and the present. Almost all the cuts are between Dresden and some other segment of Billy's life. His trip up the stairs with spot parallels his trip up the stairs of the bomb shelter; the flashing traffic light is intercut with the bombing of Dresden; the American photographer recalls the German; the plane crash throws him back to Dresden and SlaughterhouseFive; the door to his roomleads instead to the p.o.w. camp or to the annihilated city; and his son's call of "Dad" mingles with the young German's call of "Papa." He moves from the burning bodies in Dresden to Montana's arms; from the eanth of Dresden to his couch on Tralfamadore; and from the roadway in Dresden to his final triumphant moment. Billy is still a prisoner of his war experiences, even on Tralfamadore.

If all is not random and arbitrary, beyond our control, then one may be able to make choices and be accountable for those choices. Free will is still a possibility. In addition, the film makes it clear, contrary to Billy's assertion, that time is an integral part of the universe. Billy blithely tells us he is free of time. The opening shots of the film show us an extreme close-up of Billy's letter to the Ilium paper: "I have become unstuck in time," he declares. Since his conversion to Tralfamadorianism, he is no longer bound by time, and can now travel freely between past, present, and future. As he tells his lecture audience, 
moments before his assassination, there is no mortality. "It's time for me to be dead for a little while, and then live again." Resurrection is possible; life is eternal; man's age old dream of immortality has been attained. But the film questions this viewpoint. In the opening scene, before we meet Billy, we hear the ticking of a clock. As the camera moves through the house, viewing the world from his perspective, we hear the measured rhythm of the timepiece. The plane crash is preceded by the the ubiquitous barbershop quartet, singing "there'll be some changes made," an ironic line, and an aural reminder for the audience that the world is fluid, not fixed. The operating room sequence is underpinned by the sound of the respirator, its regularity a mimic clock. In two crucial scenes the clock is an integral element, serving, when contrasted to Billy's Tralfamadorian dogma, to undercut his statements. The scene with Robert, the young Green Beret, is played against the sound of a ticking clock, even though such measured ticking would not be audible during an ordinary conversation. Robert's conversion to Campbellism is the final defeat for Billy. The father-son relationship so vital to Billy with his own father, with Derby, and now with Robert has been destroyed. The myth of the family, around which Billy has built his vision of happiness, is shattered, and the ticking of the clock places this loss in the stream of time, making it part of an ongoing process. 
Later, after his election to and salvation on Tralfamadore, Billy returns to Earth to defeat his nagging daughter. He calmly explains the paradise on Tralfamadore to her, apparently overcoming the interfering female presence at last. But ever present in the background is the ticking of a clock, one more reminder of a temporality Billy insists does not exist. Finally, the penultimate scene in the movie is built around the concept of time. Billy helps Lazzaro loot, appropriately enough, a grandfather clock, and he is soon pinned down by it when the others flee the sound of gunfire. The image, in conjunction with the other reminders of time, suggests Billy is still pinned by, and subordinate to time. Billy's final claim that suffering can be eliminated is also questioned. First, we can note that an act of will abolishes suffering, a strange method for a planet without free will, and second that the narrative of the film makes Tralfamadore clearly escapist wish-fulfillment. The dome serves as a refuge from, not at alternative to, Dresden and Ilium. Even though the events in the film are non-chronological, there is still a definite narrative order. All crucial events occur within a short period of film time, and are so arranged that the pleasant ones seem a response to the painful. They are in effect intercut, and, as with all cross cutting, a relationship is established between the two incidents. For each failure he endures or pain he suffers, Billy is rewarded with a moment on Tralfamadore, and the conjunction suggests that Tralfamadore is an escape from the world. 
The two climactic moments in his life, the experiences of Dresden and the devastation of life in Ilium, are joined by the mingling of the young German's cry of "Papa" and Robert's call of "Dad." They are followed by Billy's first trip to Tralfamadore. In his talk with the voice, Billy mentions Dresden, "the end of the world," and suddenly we are there, watching the collection and burning of the bodies. As Billy stands there, masked against the diseased air, watching the bodies of the women and children piled and burned, the voice tells him the way to spend a pleasant journey. Immediately Billy is back on Tralfamadore, encountering and winning Montana--an infinitely more pleasant experience than Dresden. Not only does the voice preach escapism, but the structure of the film suggests it. Billy's next visit to Dresden reveals the senseless death of Edgar Derby, but this is quickly overturned when we cut from Billy, slammed to the earth by the guards, to Billy recumbent on his couch in the dome, talking with Montana about having a baby. After the triumph over his daughter, his death scene, and the final experience in Dresden, Billy glances to the sky to catch sight of the sun. In the film, light has served as a metaphor for the avenue to Tralfamadore. At the sight of it, Billy finds himself once again in Montana's arms, a part of his family, at long last triumphantly attaining his ideals. Life in Ilium, Dresden, and even death have seemingly been overcome, but the triumph is muted for the audience by recognition of the narrative structure. 
Tralfamadore is ultimately reduced to the status of a dream. The associative nature of Billy's "time-tripping" suggests his journey is mental, and thus Tralfamadore a mental waystation, and the contravention of the Tralfamadorian vision also contributes to our perception of it as a mental phenomenon. The perceptive viewer realizes that Tralfamadore is an escapist fantasy. ${ }^{4}$ Billy's idealistic beliefs have crumbled under the pressures of the world, and he has retreated inward to safety and security.

Our realization that Billy is deceiving himself reduces our sympathy for him. We discover that he is a dreamer, a child of fantasy whose purblind imagination has no resources other than fantasy (in this case Tralfamadore) for dealing with the horror and meaninglessness of modern life. We may sympathize with his problems, and even with him, but no longer identify with him because he and his solutions seem dwanfed by the complexity of the problems. Billy's transformation from pleasant stereotype to complex character is effected through a variation of conventions and the use of motifs. First, we can note that Billy differs from the standard naive character. Ordinarily, characters in films of this genre demonstrate their right to their success by evidencing courage, pluck, some special skill, or just the ability to survive in a harsh world. The character, like Judy Holliday in Born Yesterday, should already possess the virtues and skills, and only lack the opportunity or experience to use them. And usually the 
naive character wins some reconciliation with society, often through a romantic involvement with an acceptable member of society. Billy does none of these things. For all his good qualities, he demonstrates no special skill or virtue; he simply endures. Throughout the film he lacks the vitality, the distinguishing character, the enlightened but unarticulated wisdom, or the strength with which we can identify. Billy lacks character; as Rumford says, "I could carve a better man out of a banana." Nor does Billy triumph by virtue of his skill; he gains Tralfamadore and Montana accidentally. Nor does he effect a reconciliation with society. He attains his socially approved happiness in a world outside the recognizable social fabric.

In addition, Billy is presented as a child of fantasy, someone who understands the world in fairy-tale terms. He wears boots from the p.o.w. production of Cinderella, a story which deals with the kind of magical transformation Billy undergoes. He also talks of Dresden as "a land of Oz," and he later tells val "to follow the yellow brick road," the ribbon, to the car. The story of $\mathrm{Oz}$, with its emphasis on the permanent and abiding virtues of the honest family, also has special relevance for Billy's story. His entrance into Dresden shows him as a pied piper, a child among children, oblivious to the concerns of the war. Adult fantasies are also a part of his life, as the longing looks at the whores suggest. The drive-in scene with the Montana porno film shows the same sexual fantasies. As the nude 
princess calls to her attendant, Billy wishfully nods yes, yes to the voice.

Billy's escapist vision is further emphasized by the blanket motif. We see him wrap himself in a blanket for protection from the physically and psychically unpleasant. It surrounds him as he stumbles through the snow, and later as he trudges in the P.o.w. line. When the old timer in the box car begins talking about the hard winters in Troy (which is the Anglicization of Ilium), Billy draws the blanket over his head. We then cut to the hospital where Billy, crablike, peers out of the blanket at his mother and Mr. Rosewater. The way he shuts out his mother is emblematic of the way Billy eventually shuts out all painful experiences. But the futility of such action is illustrated in the second box car scene. Weary rips off the blanket to accuse Billy of murder, forcing Billy to witness his death.

A more telling demonstration of Billy's limitations is Hill's use of light. It serves as the medium by which Billy ascends to Tralfamadore, and thus it becomes a visual metaphor for Tralfamadore. Light's long association with poetic inspiration may also be operating here, and Billy's ability to accept and incorporate Tralfamadore is evidence of his open imagination. However, in the film light also reveals not only the familial paradise of Tralfamadore, but also the grotesque world of Dresden and the war, the symbol of death and horror here on earth. Billy's positive use of light contrasts with the more negative use made of it in 
the film, and the discrepancy again suggests that Billy is myopic, that his vision is selective.

In the world of the film, light reveals more than happiness. In the box car, the German guard's weaving flashlight intermittently reveals Weary's frozen face. The searchlights in the p.o.w. camp illuminate not only the singing, vivacious British, but the brutish Russians as well. The composition of the shots of the two groups is similar; light above and behind illuminates both Russians and the cheerful welcoming party of the British. Later the blinking, shaking light of the bomb shelter creates a pattern that matches that of the incendiary bombs walking across Dresden, and that in turn is intercut with the blinking red traffic light. Light thus triggers associations with Dresden as well as Tralfamadore. When candles are lit in the bomb shelter, the bottom lighting creates grotesque shadows; the German commandant's head, for example, becomes a death mask. And the movement from the protective dark of the shelter to the light of day and the annihilated city typifies the relationship between light and dark in the film: one reveals, the other conceals.

Even the Tralfamadorian light is associated with death. Its first appearance coincides with Billy's eviction from his son's christening party. As the song in the background ironically proclaims "true love will come shining through," Billy sits despondently on the lawn. The Tralfamadorian light comes down, shines briefly, and disappears. Billy 
follows it into the sky. The camera rests on the sky briefly and momentarily we hear Lazzaro's voice, once again threatening Billy. The point seems clear: The same sky which houses Tralfamadore houses Lazzaro. Later, on Tralfamadore, Billy and Montana will ask for the night canopy so that they can get acquainted. The camera pulls back to reveal the dome against the heavens, then pans right, the stars gradually dissolving into the reflections from the Dresden china figurine in Derby's hand. Once again the film suggests that Dresden and Tralfamadore are a continuum, not separate entities, and that Billy has selectively chosen those elements he wishes to see.

Billy Pilgrim, then, fails to be the classic American hero. His voyage is not one outward to discovery, but inward to fantasy. He creates a vision of happiness that protects more than Derby's idealism or Val's materialism; divorced from reality, it protects his reality. Fantasies are not necessarily harmful or escapist, but Billy's is obviously a retreat from the problems created by his wartime experiences.

The film questions the dream and the dreamer, and thus asks that we examine the values associated with the fantasy world. It offers no solutions of its own to the problems that defeat Billy, and perhaps that is a major fault, but it suggests that the spiritual homilies we take for granted-the exaltation of family and virtue--are insufficient also and in need of revision. Through its ironic mode, the film 
makes the discovery of the limitation of traditional beliefs seem our own, and its point is made more forcefully than something didactic like Johnny Got His Gun. No longer will the audience be allowed, as Biliy suggests, "to ignore the bad moments and concentrate on the good."

Slaughterhouse-Five shows one man's, an Everyman's, inability to cope with the complexity and difficulties of modern life. 5 And, like Butch Cassidy, it lays the blame for this problem on the antiquated assumptions of the culture. The examination of the cultural conventions, however, is far from complete, for Hill, in his next film, continues to explore, again through genre, the American social fabric.

\section{Notes}

1

Typical is Charles champlin, in a review for the Los Angeles Times, 24 March 1972 , partially reprinted in "Slaughterhouse-Five," Film Facts, ed. by Ernest Parmentier, 15, No. 5, 1972, p. 93. Champlin writes that "Slaughterhouse-Five is perhaps not intellectually profound, but it is impassioned, warm, human and positive. Its last images are of a blissful nursing mother and happy father in a kind of geodesic heaven with decor by Sears set amidst styrofoam clouds beneath a Rodgers $\&$ Hart moon. It's a multi-message which I think can be said to say that the terrestrial and celestial paradise may not be that different; the trick is knowing and appreciating what the earthly treasures are. The power of Vonnegut's work is that he reads all the bad vibes in the world, the horrors, the cruelties, the insanities, but counterattacks with kindness, love, forgiveness and understanding, virtues which grow more fantastic every day."

Other critics who liked the film generally agreed with Champlin's reading. See, for example, Arthur Knight, "Space Craft," Saturday Review, 15 April 1972, Pp. 10-11; Colin Westerbeck, "The Screen," Commonweal, 96, 28 July 1972, pp. 405-06; and Daniel Brudnoy, "Films," National Review, 24, No. 32,18 August 1972, pp. $911-12$. 
Those who disliked the film did so because they felt the optimism was muddled or unjustified. For example, Paul Zimmerman, "Pilgrim's Progress," Newsweek, 79, 3 April 1972 , p. 85; Stephen Farber, "Slaughterhouse': Return to Shangrila?" The New York Times, 11 June 1972, Sec. II, P. 13, col. 1; and stanley Kauffmann, "On Films," New Republic, 166, 13 May 1972, p. 35 .

2 Harold Lloyd and Jerry Lewis made careers out of playing just such characters. See Stuart Kaminsky, American Film Genres (N.P., 1976), PP. 160-70.

3 This argument might counter those critics who found the time-tripping uneffective. See Vincent Canby, rev. of Slaughterhouse-Five, The New York Times, 23 March 1972, p. 51 , col. 1. Also, Penelope Gilliat, "Slaughterhouse," New Yorker, 48, 1 April 1972, p. 53.

4 Richard Shickel, "An so it goes--onscreen," Life, 70, 28 April 1972, p. 16, suggests "the withdrawals and fantasies. . are Pilgrim's principal defense against the terrors of the times and finally become his principal reality."

5 Canby, p. 54, col. 1, and Kauffmann, p. 35, both suggest Billy is meant to be "Everyman." 
CHAPTER IV

THE STING

It would seem a contravention of critical and popular taste to assert that The Sting (1973), Hill's most commercially successful film, is more than slick entertainment. But the assertion can be made. As do all Hill's films, The Sting questions a cultural convention, in this case the commonly accepted belief in the efficacious operation of morality and justice. It shows that concept to be inaccurate at best, an idealized conception of the relations between and the nature of men. A sincere belief in it leads only to misconceptions which, if too blindly followed, can cause fatal mistakes. Johnny Hooker, the central character, wants to avenge the unjust death of his old friend, Luther coleman. He is motivated by a certainty that there is an order to the world, and we sympathize because we share his certainty that an act of vengeance will be an act of reparation for Luther. Justice will be satisfied, and wrong will once again be counterbalanced by right. But the emotional involvement that fires him turns out to be detrimental, for it pushes him into situations (his affair with the waitress) filled with danger. He learns instead that he is better off to deny the possibility of justice and a larger ordering force; 
a concern for others or for a social order is seen as counterproductive. The proper pursuit of man is the cultivation of the self; his energies should be focused on enterprises which yield the greatest sense of self-satisfaction, for this is the only worthwhile goal for an individual. Hooker's last minute epiphany subverts the conventional response to the film. Instead of a comfortably familiar ending, we must reexamine the old moral conventions denied by Hooker and evaluate the new, self-centered doctrine implicitly urged by him. The conventional story is transformed into an exploration of contemporary morality, something far different than expected.

Such an interpretation admittedly flies in the face of accepted critical opinion. Most critics, while admitting the film's commercial potential, dismissed it. Pauline Kael, who led the onslaught, is typical in her remarks. The Sting . . . is meant to be roguishly charming entertainment, and I guess that's how most of the audience takes it, but I found it visually claustrophobic, and totally mechanical. It keeps cranking on, section after section, and it doesn't have a good spirit. . . the director is the implacably impersonal George Roy Hill. The script, by David $S$. Ward, is a collection of Damon Runyon hand-me-downs with the flavor gone. ${ }^{1}$

Paul Zimmerman of Newsweek found it enjoyable, but stale, light entertainment. ${ }^{2}$ Stanley Kauffmann and Colin Westerbeck concurred, with only John Simon giving unqualified approval. ${ }^{3}$ No serious film journal bothered with a review, but some critics did find it more than mechanical. Stanley solomon, in Beyond Formula, saw it was a well-done and enjoyable variation of the big caper film. 4 
I would suggest both these schools of thought are in error. The film is neither vapid imitation or masterful variation; it is an exploration through a genre story of the metaphysical conventions that uphold the genre and the society that endorses it. It asserts the antiquity and inappropriateness of those metaphysics, implicitly disputing what is so often unquestioned. We can see this if we note (1) the ways in which the story conforms to the conventions of the genre, (2) the ways in which it differs from the genre, and (3) the implications of the relationships between the genre story and the variations of it.

The Sting is obviously a genre story, a big caper film. According to Stuart Kaminsky, in American Film Genres, a big caper film has a conflict between individuals and an impersonal society, a concentration on an elaborate scheme to steal massive amounts of money, a requirement of great skill to achieve the goal, an understandable and sympathetic reason for the commission of the crime, and success. 5 Hill's story meets all these criteria. The two distinct individuals, Hooker and Gondorff, work against a large, impersonal force, represented by Doyle Lonnegan; their elaborate scheme requires great amounts of skill; and we emotionally endorse the con artists, not only because they are more human and engaging than Lonnegan, but also because their motive--revenge--is understandable and sympathetic in the context of the film. And, of course, they succeed. Stanley Solomon asserts that the crime film must establish 
a moral heirarchy, with some criminals more sympathetic than the others; work with a plot that requires great skill; give an understandable motive to the protagonists; and grant them success. The Sting also meets his genre criteria, for it, as Solomon notes, "provides a brilliant example of how the genre creates a reasonable facsimile of moral order within a situation that in a real-life equivalent would be beyond moral considerations." 6 As Solomon sees it, "Redford's motivation is revenge against the man who ordered his colleague's murder." ${ }^{7}$ In spite of the complex plot, "the overriding issue is clear; Redford and Newman risk their lives to pull off their confidence game, not for the huge sums of money they can gain from it but, on Newman's part, for the sake of the artistry of his plan and his affection for Redford and, on Redford's part, out of a desire to revenge his murdered friend." 8

In addition, we can note features from other genres that are part of The Sting. The protoganists exemplify figures who, because of their knowledge and skills, can effect justice in cases beyond the reach of the law. Private detectives, such as J.J. Gittes in Polanski's Chinatown and Sam Spade in Houston's The Maltese Falcon, are obvious examples of this type of character. The protagonists also share qualities with the con artist figure, another staple of American popular culture. For example, they, like the George C. Scott character in The Flim-Flam Man, or the Ryan O'Neal character in Paper Moon, attract because they 
possess more wisdom and moral character than those who are bilked. They succeed because of the greed or stupidity of others, seldom conning those who are good. Associations with such character types only strengthen the familiar aura that surrounds Hooker and Gondorff.

The most important point in the big caper film, for both Kaminsky and Solomon, is motive, and this essential characteristic deserves some elaboration. The con men gain our sympathy because their desire to avenge Luther's death implicitly affirms a concept central to the American understanding of the world. The idea of justice, a moral-legal system that operates to reward right and punish wrong, is ingrained in most Americans. As children they learn that those who transgress are punished, certainly in the afterlife and usually in this life. The concept places evil in perspective, and comfortingly assures believers of the eventual triumph of a just, benevolent world. The con artist's revenge is not the pointless, irrational vengeance of the Lee Marvin character in Point Blank, the Glenn Ford character in The Big Heat, or the Tab Hunter character in Hell to Eternity; it is rather a just punishment of a criminal who is beyond the law. We sympathize with the con men because their action represents the operation of the justice in which most still unthinkingly believe. It is essential that we consciously as well as intuitively understand that this conventional precept forms the base upon which the Sting is built. 
However, there are significant variations from the expected genre conventions which combine to create a second narrative that stands juxtaposed to the genre story, its existence challenging the conventions upon which the genre story is based. Essentially, the typical genre story moves from a troubled situation to a positive resolution. Even if the criminals are caught, it is usually after the successful completion of their caper, and their small victory against the impersonal establishment has been gained. In The Sting, the con men's seeming victory is shown as a hollow "triumph" by the second narrative. The film does not reaffirm any conventional beliefs about justice--in fact, it denies that justice can be obtained--and thus it challenges the basic conventions of the genre. The Sting asks us to look again at what seems obvious and given. Before discussing the variations that create the second narrative, I would first like to show how Hill encourages a critical questioning of the genre story by the use of artifice. By presenting the film as a work structured for a purpose, by defusing the commercial illusion that we are watching a self-contained, complete world, Hill stimulates a critical, distanced attitude that moves us beyond the stock response to genre films. ${ }^{10}$ Attention focused on the artifice prevents attention to the characters, and the distance that results makes it easier and more natural to question both them and their motives. 
The opening and closing titles serve as a frame which calls attention to the role of manipulation in the film. Drawn in the Saturday Evening Post style associated with the thirties, the titles seem a calculated commercial ploy, but we should note that four of the five (the first is the only exception) make some indirect reference to the film as constructed work. The second shows the characters in costume on a set, with director Hill looking on from the left; the thind, writer Ward looking on another set from the right; and the fourth, the two masks that are the traditional symbols of performance. The ending title shows workers dismantling the wire-shop props, another reminder of the structured nature of the film. Significantly this is preceded by a momentary break between the final iris-out and the last title during which we hear Marvin Hamlisch's voice counting out the beat for the musicians. The obvious deliberateness of the break and the subject of the final title bring us back to the starting point: What we have watched was put together, and we are meant to note its constructed nature. Within the film proper, the wipes and irises contribute to our consciousness of artifice. By their very nature, these devices, rejected by most filmmakers because of their obviousness, call attention to the making involved in filmmaking.

The story also contains several incidents that contribute to the distancing effect suggested by the titles and transitional devices. By emphasizing that appearnce is 
manipulative, the scenes implicitly ask us to step back and examine the phenomenological world more carefully. The two biggest surprises in the film, for most, are the revelations of the Sallino and FBI sub-plots. Each works because the audience brings stock expectations to the incidents. Most assume that Loretta is the love-interest; she seems honest and lonely, and aids Hooker in his escape from the gunman. Our attention is focused on the black-gloved man who, with his stylized dress and Italian features, seems a more conventional threat. Such judgment causes a reversal of expectations in the alley gunfight that, while in one way a source of pleasure, serves as an implicit reminder of the inadequacy of stock responses. The "death" scene is even more of a surprise because once again the audience accepts conventions so unhesitatingly. The deaths of Cole and Sallino are filmed in the traditional Hollywood stylized manner, with bright red aniline dye and no excessive gore. The final scene is shot in exactly the same way, and we assume the characters are dead. When they pop back to life, we cheer, because the surprise makes the Mick's loss more complete. But the reversal of expectations, forgotten in the triumph, is equally important. By playing with accepted conventions, conventions that the film itself uses in earlier scenes, Hill calls attention to the artificiality of the surface, pointing out that anything can be manipulated for effect. 
In addition, the film as a whole can be seen as a series of incidents structured for effect. We are continually confronted with scenes in which appearances have been manipulated, and these scenes provide not only entertainment (because we usually are aware of the manipulation), but, when taken as a group, remind us of the illusory nature of any surface-including, by extension, the film itself. The opening scene shows the numbers operation delayed by a "raid" meant to keep up the mayor's reputation for honesty. The first con involves an attempt by the numbers runner to trick the two men (he promises them their money will be safe with him) as well as the con of the numbers runner by the grifters. We also witness the crooked gambling den in which Hooker loses his money, the counterfeit money that buys time from Lt. Snyder; Hooker's cheery disposition, which masks his despair at losing the money, and his calm acquiesence, which masks his anger at Luther's retirement; Hooker's continued silence about the pursuit of the thugs and snyder; the transformation of Hooker into "Kelly"; the refined surface that hides Lonnegan's crudity; Lonnegan's attempted con of "Shaw"; Loretta Sallino's performance; the revelation of the blackgloved man's purpose; the Western Union ploy; all the action in the wire-shop; the FBI drama enacted for snyder; and, of course, the "death" scene. In every sequence we discover that there is an additional dimension to the situation which, when perceived, alters our understanding of it. The characters (and occasionally the audience) are deceived 
only because they bring certain assumptions to the incidents instead of relying on objective evidence and their own ratiocinative powers. (For example, we assume the con men are dead; the audience and Hooker assume Loretta is honest; and Lonnegan assumes that "Shaw" is no match for his powers.)

The critical attitude encouraged by the titles, transitional devices, and the story makes us sensitive to the ways in which the characters differ from the usual genre figures. The first significant variation is the linkage of the con men to Lonnegan. We gradually discover that there are similarities between the two groups, and this prevents the total sympathetic identification common in most films of the genre. ${ }^{11}$ Lonnegan and Gondorff, for example, despite their obvious differences in personality, characteristics, and goals, share a number of traits. Both men are directors of organizations, and both use their subordinates to further their own goals. In the card game sequence, both men are performing. Lonnegan, crude, emotional, and vicious, hides behind a mask of refinement and rationality; Gondorff hides his intelligence behind a facade of vulgarity and simplicity, playing the fool for others. Both men cheat, but neither for monetary gain. Lonnegan wants "to bust that bastard bookie once and for all"; Gondorff must prod Lonnegan into revenge. Obviously, the central action of the picture, the unfolding of the sting, involves both men in the same sort of role playing. Lonnegan pretends to be a bettor, Gondorff 
a bookie; Lonnegan wants to revenge and enrich himself, while Gondorff wants revenge and the pleasure of seeing his plan work. Both are masters of illusion who recognize the importance of facade. Lonnegan tells Floyd he must kill in order to preserve his image of strength, to keep others from testing him. Gondorff tells Hooker that "you've got to keep his [Lonnegan's] con after you take his money"; the illusion must be maintained to forestall revenge. And both are willing to play rough to maintain their facades. Lonnegan has his men kill Luther so that the illusion of omnipotence can be kept; Gondorff has his friend protect Hooker by killing Sallino, again in order to protect the illusion of the wire-store. The fact that neither man pulls the trigger does not mitigate their responsibility for the killings; nor does the fact that the action is directed against criminals alter the immorality of the act. ${ }^{12}$ We excuse the con men because their motives seem to justify such actions, but later even this judgment must be altered.

Hill also uses editing and composition to suggest a union between the two groups. Several match cuts throughout the film join the movement of members of both groups. For example, after Hooker loses his money and his date, he moves right to left down a street; the picture then wipes to a car moving right to left toward Lonnegan's headquarters. Shortly thereafter we cut from Floyd moving right to left away from Lonnegan to Hooker moving right to left up the stairs to Luther's. The transition between the golf course scene and the first merry-go-round scene is made with 
a reverse spin that joins the motions of Floyd and Gondorff. Later there will be similar reverse spins that move us from Hooker's face outside the wire-shop to Loretta's at the cafe, and Snyder's visage in the FBI headquarters to Gondorff's in the brothel room. Such transitions subtly suggest a union between two worlds that convention demands be kept separate.

Lighting and composition also associate the con men with Lonnegan. For example, there is a strong vertical motif used in connection with both. The opening shot follows Mottola up the stairs, the vertical motion joined with the horizontal lines of the steps. Immediately after the first con, Hooker and Luther are associated with vertical lines, which, with their connotation of prison, suggest criminal activity. They are framed through a gate with vertical slats, and run through it, pausing in the vertical shadows. The window just behind Hooker is blocked with vertical bars. After they split, Hooker is seen through the vertical bars of the pawn shop, buying the egregiously garish suit. On three separate occasions, high angle shots of Hooker entering an apartment building are framed through the vertical slats of the bannisters. Also, the vertical Iines created by the merry-go-round poles adumbrate this compositional device, as does the vertical movement of the freight elevator in Lonnegan's packing house (as a freight elevator, it is constructed of vertical slats) and Hooker's ascension in the hotel elevator. Lonnegan is framed by the vertical 
bars of the cashier's cage, and for a moment Gondorff stands beside him, also framed by the bars of an adjoining cage. The vertical motif, with its suggestion of prison strongest in this shot, makes the two leaders seem well-dressed prisoners in adjacent cells.

A horizontal motif is just as strong. Almost all the interiors in the film seem shaded by venetian blinds, and the light filtering through them casts a shadow which again reminds one of prison. The room in Lonnegan's packing house is shuttered with blinds, and as he stands in the gloom the light casts horizontal shadows across his chest. Gondorff's office is similarly enclosed, establishing yet another link between him and Lonnegan and he is seen as a shadow behind the blinds. Hooker, just before he leaves the diner, is also bathed in the horizontal shadow of its blinds. The similarity of the lines seems intended to connect all three men, particularly when the unnatural lighting of these situations is considered. Lonnegan stands facing a wall, but the blinds still somehow cast a shadow; Hooker faces an empty, windowless counter, yet again there are shadows falling across his chest.

The suggestion of union beneath the surface is a signifcant variation of the genre conventions, but the greatest difference between the characters and our expectations of them involves their motive. The importance of motive has already been discussed; it is essentially the justification for their actions. We pardon their immorality, such as 
cheating in the card game or murdering Sallino, because the revenge motive is a sympathetic one. However, as the picture progresses, we discover that the con artists are driven as much by self-interest as revenge, and that they have only a minimal commitment to the concept of justice. This revelation alters our understanding of them and their actions, and questions their role as unqualified heroes. Most critics and viewers assume the con men are motivated by revenge. Solomon is typical when he says "Redford's motivation is revenge against the man who ordered his colleagues murder . . the overriding issue is clear." 13 But contrary to that statement and the general belief, the primary stimulus is self-gratification. The sting serves as an opportunity for Gondorff to prove himself, just as crime served as an opportunity for Butch and Sundance to prove themselves and the battle with Kessler as an opportunity for Waldo to prove himself. Through the successful perpetration of a crime, Gondorff defines himself as an individual; the success gives him a sense of identity. The fact is not revealed until late in the film, until we have already committed our sympathies to the con men, but it cannot be ignored. Gondorff implicitly tells Hooker that he was never interested in money or security. He had those years ago when he worked with a mob that fleeced with impunity, but did not like the benefits. "No use being a grifter if it's the same as being a citizen." Gondorff is an artist who cons to show his skill, to exercise his 
virtuosity. Apparently the pleasure of proving himself a successful, distinct individual motivates him, and this motivation is eventually conveyed to Hooker.

Originally Hooker shared that view. We remember his comments to Erie that he "liked grifting," and had no intention of settling down or realizing any gain. However, Luther's death has pushed him away from his self-interest; he now wants a just vengeance against Lonnegan, and he lets his emotional commitment to that drive him. He is so intent on revenge that he does not listen carefully to what Gondorff has to say. In the first meeting between the two men, Gondorff intimates that vengeance (justice) is not possible. The master con man is reluctant to take on Hooker because he does not "want no hothead looking to get even coming back halfway through saying it [the con] ain't enough [to avenge Luther]-because it's all we're going to get." Hooker overlooks that remark, even though his actions indicate that he senses Gondorff's lack of commitment to the principle of vengenance. He refuses to tell his friends about the pursuit of Lt. Snyder or Lonnegan's torpedoes because he is afraid that Gondorff will, as he promised, "fold the con" should the danger become too great. This indirectly shows that Gondorff does not believe in a quid-pro-quo system of justice, and that he would move on, without revenging Luther, with no regrets. Later, in a crucial scene in Gondorff's room, the older man makes his point explicit. Hooker apologizes for the danger, saying he would not ask 
such a sacrifice except for Luther. But Gondorff flatly states that he is not doing it for Luther: "Revenge is for suckers; I've been grifting for thirty years and I never got any." Asked why he is doing it, he shrugs: "It seems worthwhile, doesn't it?" Hooker again overlooks the remarks, perhaps because he does not understand them, but finally comes around to Gondorff's point of view. After succumbing to his emotions and spending the night with the waitress, he seems to undergo a metamorphosis after her attempt on his life. He returns to the wire-shop and exchanges a glance with Gondorff, a tacit indication that he has learned his lesson. The two men have reached an understanding. "You're right," Hooker says at the end, "it's not enough-but it's awfully close." It satisfies his urge for revenge, even though he now realizes that a simple, appropriate punishment will never be possible.

What we see, then, is an admission by both men that there can be no revenge and, by extension, no justice. They have no belief in any ondering force or that right will punish and balance wrong. Instead, they realize that the experience itself is its own reward and success proof of one's existence and identity. The refusal to take the money is not one last magnanimous gesture, but a measure of the con men's commitment to the principle of self. Knowing that they have succeeded is a much greater reward than money or the satisfaction of revenge. The motive, then, is a combination of revenge and self-interest, with the accent on the 
latter, and we must now ask ourselves whether that motive exculpates satisfactorily their duplicity and murder.

Once we combine the variations from the genre conventions we perceive the second story that shadows the first. The genre story shows the big caper; the counter genre story shows Hooker's growth to the realization that, since there is no ultimate justice, he must primarily be concerned with himself and the artistry of his activities. It is possible to discount the variations and see the film as a masterful example of the big caper film; it is also possible to accent the variations and show the film a denial of the concepts of equal justice and an ordered, meaningful universe. But the film is best served if we see the relationship between the two differing stories, for at least three thematic thrusts can be discerned.

First, the film contraverts the commonly propounded American belief in the efficiency of justice and morality by showing that the characters' success comes after they deny the possibility of avenging Luther (thus making their humiliation of Lonnegan something other than vengeance or the exaction of justice). The traditional concept of the genre is challenged as false and inadequate. In the world of the film events are arbitrary and not necessarily meaningful, and Hooker's belief in justice causes, not solves, his problems.

Second, the film reveals the hold of this perhaps inadequate convention. The audience so believes in the 
operation of justice that it accepts whatever seems to fulfill the convention. The con men appear to avenge Luther, so we assume that they have done so. Few question their motives or their actions; few question their goals; and few question the similarities in motivation (both the con men and Lonnegan are seeking to prove themselves through the con; the heroes through their success, Lonnegan through the acquisition of the money he associates with respectability and power) and modus operandi (both play roles and use force to achieve their goals) that unite the groups beneath their superficial differences. The audience wants to believe and it does believe, despite the film's intimations to the contrary. The last minute reversal occurs too late to check our sympathetic impulses, and most are carried along with the genre conventions to the "happy" ending. Only in retrospect can most see that the film has constantly questioned appearance and provided clues throughout to prevent unthinking identification with the con men. But whether we become disaffected with them during or after the film is immaterial. The experience should teach us the inadvisability of letting our emotions and the ideas of the past do our thinking for us.

Third, the film shows what happens without morality: a might-makes-right, success conscious world of the con men. Since they have no other standard of defining the self-such as service to others, the fulfillment of a moral code, or even gain--success becomes the prevailing criteria. 
Doing something well, and preferably aesthetically, serves as its own justification and reward. The sting excuses, for them, the question of the murder of Loretta Sallino; it is not a moral question, only one of efficacy: Does her killing aid or hinder the plan? Such an attitude, which is similar to Lonnegan's, should shock us as much as their denial of justice, for their new world is as hollow as the old conventions are inappropriate.

Ultimately, we see that the film explores the moral character of our society. It shows the inadequacy of the old conventions and the amoral world that results from their collapse; and the similarity of that world to our own should force us to reexamine our moral beliefs and their applicability to the modern world. The Sting probes the cultural metaphysics reflected in the genre conventions of the caper film, demonstrating Hill's mastery of commercial and cinematic art, and continuing the social criticism begun in Butch Cassidy and Slaughterhouse-Five.

\section{Notes}

1 Pauline Kael, rev. of The Sting, New Yorker, 49, 31 December 1973, pp. 49-50.

2 Paul Zimmerman, "The Smiling Monopoly," Newsweek, 82, 17 December 1973, p. 92.

3 stanley Kauffmann, "On Films," New Republic, 170, 2 February 1974, p. 20. Colin Westerbeck, "The Screen," Commonweal, 100, 12 April 1974, pp. 133-34. John Simon, "Films," Esquire, 81, March 1974, p. 72. 
p. 167.

4 Stanley Solomon, Beyond Formula (New York, 1976),

5 Stuart Kaminsky, American Film Genres (n.p., 1976), pp. $74-86$.

$$
\begin{aligned}
& 6 \text { Solomon, P. } 168 . \\
& 7 \text { Solomon, p. } 169 . \\
& 8 \text { Solomon, P. } 169 .
\end{aligned}
$$

9 Kaminsky, p. 82, notes that "revenge against the establishment is a frequent motive for the leader's actions." The leader's "gathering of the gang and execution of the crime affirms to him his own ability and the collective ability of the men to beat the system which disdains them." The con men are somewhat similar in that they are revenging themselves against a force (Lonnegan) that denies their rules, values, and feelings have any significance. Their con will prove that justice applies to Lonnegan, and affirms their values of camaraderie, loyalty, etc.

10 For typical comments on the commercial movie's illusion of integrity, see Allan Casebier, Film Appreciation (New York, 1976), p. 62, and James Roy MacBean, Film and Revolution (Bloomington, Indiana, 1977), pp. 122-23 and passim.

11 Kaminsky, P. 69, notes the need to make the protagonists sympathetic, and, p. 78, that the antagonistic force is almost always monolithic. In the typical genre film, the two opposing forces are not joined.

12 Solomon, p. 168, suggests we do not make moral judgments of criminal action directed at other criminals. But, while partially true, the statement is an oversimplification. Although the criminal world may be alien to our own, we continue to make emotional and moral judgments on it, applying our values to the characters and their actions. Circumstances may mitigate our judgments somewhat, but they do not alter them. A crime such as murder remains a crime unless there are significant ameliorating circumstances, such as self-defense. 
CHAPTER V

THE GREAT WALDO PEPPER

In The Great Waldo Pepper (1975), Hill returns to the romantic concept of individualism, a subject which he first touched on in Butch Cassidy. In that film, the primary focus was on the outlaws' struggle to fulfill a romantic ideal and the difficulties encountered because of their lack of understanding. In Waldo Pepper, Hill has enlarged his perspective and shifted his focus. He now considers the process by which the myth grows and focuses on the cost for the individual who strives to achieve the romantic ideal of heroic individuality. The film shows that the conventional belief in the grandeur of heroism, the assurance that success guarantees happiness, wealth, and fame, is erroneous. Instead, Waldo discovers that the pure exhilaration of the heroic moment is evanescent and unique; it is understood only by the participants, and has no currency in the everyday world. In addition, Waldo's growth to knowledge reveals to the audience the tremendous personal cost of attaining the transcendent moment. Contrary to popular wisdom, which makes success seem available to any diligent worker, the film shows that the transcendent moment may require a total sacrifice of self. The Great Waldo Pepper explores 
the nature of individual heroism, showing the rewards and the costs in a new, unconventional light.

Hill develops this understanding of heroism through irony, which most critics, who regarded the film as a conventional success story, missed. 1 This film follows Waldo from the time he announces his quest to become the "greatest flier in the world," through a series of trials, including his poverty, work in the air circus, and the bureaucratic interference of the government, to the climactic encounter with Kessler. Through it, Waldo seemingly gains the success and happiness associated with the traditional myth of heroism. Ordinarily, the American hero is honored, admired, and, in his control of his particular environment, secure. He has achieved a mastery of himself and his world unattained by the many who seek this psychic, spiritual, and financial security. The hero is identified by his success, for in the American scheme success equals heroic achievement equals individualism. To succeed is to prove one's worth and internal stature. Almost all American heroes have accomplished more than or gone beyond the limits of the ordinary man, gaining in their success distinction and a guarantee of happiness. The hero's marriage.is to a beautiful, loving woman; his children are models of and credits to him; and his life has value, worth, and meaning. He is loved and respected by all, a friend to many, and a model for others to emulate. Though the myth is false, and many consciously recognize that falseness, the overwhelming majority of people 
still believe in it. Waldo Pepper is one of them, and his story details an attempt to attain that mythic success.

The film, though, by manipulation of conventional responses, undercuts this traditional myth by showing it as false and misleading. False because it takes the triumphant moment, the attainment of success, and eliminates whatever danger, suffering, or death accompanied it, reducing it to an attractive, painless, eternally beautiful, and readily available commodity. Misleading because it asserts that the attainment of success somehow provides solutions to problems like loneliness, unhappiness, or despair. Waldo's belief in the myth testifies not only to his sense of dissatisfaction, but also to his limitation. Only at the end does he reject the traditional myth and move to a new understanding of the nature of perfection and the danger and the cost of pursuing it.

The film examines the myth by working variations on the conventional narrative, in effect juxtaposing a traditional and non-traditional understanding of success, and moving us toward a new, more critical view of the myth. The traditional story is so familiar that it needs only to be outlined. The central character, motivated by a desire for perfection or a hope of aiding others, pursues a goal that seems beyond the reach of ordinary man. To achieve it, he must overcome many obstacles, eventually triumphing and bringing benefits to society or else reaffirming the limitless potential of the human spirit. Almost always, success 
means happiness: personal happiness in the achievement of the goal, and financial, emotional, and social success as a result of that achievement.

But the film departs from this narrative. First, there are several broad variations in character and plot that alert us to the unconventional nature of the film. Waldo, for example, is unable to refute the farmer's challenge to the sanctity of his goal. As waldo sits with the farm family, enjoying dinner, the farmer questions Waldo's choice of Kessler as a hero. "Shooting down Americans don't make a man a hero to me," he says. Waldo ignores the challenge, claiming, but not explaining, that Kessler's different. When the farmer asks if waldo is going to devote his life to stunting, Waldo confidently launches into a discussion of his stunt plans; he again misses the implicit challenge of the man's remark. Later, Waldo is revealed to be a liar, and the Kessler story, Waldo's proof of his heroic stature, shown to belong to another. Such mendacity upsets our conventional responses to Waldo, termporarily distancing us from him, but it is a minor fault compared to his unsuccessful attempt to rescue Mary Beth. That comes as a shock to most, not only because the film has been played as a farce till then, but because we do not expect a hero to fail in so crucial a situation. The same can be said of his attempt to rescue Ezra. Once again Waldo cannot effect some proof of his extraordinary ability. Thus his triumph is curiously ambiguous. His battle with Kessler seems more the result 
of accident than an earned contest, and his victory is without the usual acclaim, resolution of any problem, or reconciliation with society. The flight into the heavens seems a denial of the usual understandings of achievement. The film does not explicitly affirm the doctrine of success and the glory of heroism, as do most traditional commercial films, such as White Line Fever or Star Wars. These variations were not unnoticed by critics, but were dismissed as cold calculation or else proof that Hill could not control his material. ${ }^{2}$ However, their purpose becomes clearer if we note some more subtle variations from the traditional conventions of success stories. Once they are perceived, the film becomes something more than a paean to Boy scout virtues or a muddled attempt to explore significant issues. In traditional stories, the hero perceives value in certain actions or conditions, pursues that goal, and in attaining it gains some measure of happiness or satisfaction. The motive is hardly ever self-aggrandizement or financial gain, but almost always a quest for perfection or a desire to aid others. Richard Shickel sees Waldo as a member of this selfless group.

One must not think of Waldo (Robert Redford) as merely a danedevil, idly tempting fate. Rather, he is a distillation of the romantic attitude common among the first generation of aviators. Their feeling was that the suddenly accessible sky offered not just a beauty and a freedom the earthbound could never know, but a purifying simplicity as well. In those early days, there were well-known limits of performance against which one pressed, hoping through technique and aeronautical invention, to redefine them. There 
was also a direct correlation between talent and success (which could be defined simply as survival) that seemed unknown on the ground.

This is not entirely so in Hill's film. The characters pursue their goals, such as being the greatest flier in the world because of the glory and wealth associated with success. Waldo is the clearest example of this motivation. During the discussion with Maude about the Outside Loop, Waldo explains that doing it would make him and Ezra "very rich and very famous." ${ }^{4}$ Waldo is so enthralled by the idea of glory that he fabricates proof of his heroism to satisfy his desire for it, as is demonstrated in his telling of the Kessler story. When exposed as a liar, he only says forlornly: "It should've been me." There is no remorse, only a regret that he could not fulfill the requirements of the heroic ideal. The strength of this need is also demonstrated in the prelude to the rope climbing sequence. The camera opens on a sign that reads "Lessons...Rides... Stunts... Best in Area" and then moves up to reveal Waldo's disabled plane standing in an empty field. The disparity between the sign and the reality demonstrates the importance of the projected image to Waldo. Like Axel with his "Stunt King" sign, and Dillhoefer with his everchanging circussign, Waldo feels he must put forth a larger-than-life persona. (The need to insert the word "Great" into his name is another example.) The dependence on the persona is clear in his response to Mary Beth's arrival. Waldo throws down his rags, dons scarf, cap, and goggles, and jaunts smilingly out to meet her, the image of boyish gallantry. 
Another indication that Waldo is motivated by selfish concerns comes from a comparison of his character to Axel's. Axel serves as Waldo's doppelganger, the moderate plebian self he could have become. Axel counterpoints Waldo, and is a balancing force that gives us anothen perspective on Waldo's drive for success. Not only do both men work the same profession and use the same line, but they are dressed similarly and mirror each other's gestures during their first meeting. We learn also that they share the same background. While Waldo wished to be in the 14th Scouts, fighting Kessler, Axel was in the 14th Scouts. They have similar wartime experiences, pursue the same dream of flying, are attracted to the same girl, and become a performing team. Thus, Axel's actions become an implicit comment on Waldo's actions. Axel's refusal to fly after Mary Beth's death, and his acceptance of the Hollywood work for money, not glory, shed additional light on Waldo's single-minded pursuit of fame. Waldo's course is not destined or fated, but is a choice, and should be evaluated as such.

The most obvious contrast between the two men occurs in the scene following Mary Beth's fall. Her unexpected death shocks, and also serves as evidence that the pursuit of glory is dangerous. But Waldo cannot see that danger or feel too deeply for Mary Beth because he encounters the threat of bureaucratic regulation in the flaccid form of Newton Potts. That enemy is immediately obvious and reprehensible to him, and Waldo responds energetically to the 
threat. His concern is with flying and the opportunities to prove one's self that itprovides, and this need far outweighs any concern for a fellow human being. Axel, on the other hand, sees the complexity that waldo will not; he realizes that death is a part, perhaps the greater part, of the search for glory. He abjures the childish aggrandizement of self, calling the stunt flying "kid stuff," and retires from the air circus. Axel will not ignore the human dimension Waldo overlooks, and his actions here comment on Waldo's insensitivity.

Mary Beth and Ezra are also motivated by a similar need for success, and thus their actions also serve to comment on Waldo's. In them we see the nearsightedness and lack of understanding that can lead to fatal mistakes; their commitment to the ideal of success blinds them to the danger present in their actions, and their failures warn us of the nature of the pursuit of fame. Mary Beth is an extreme case. She is so infatuated with the idea of fame that she loses her grip on reality, becoming unable to distinguish between her dream world (that of Hollywood films) and her waking life. She wholeheartedly accepts the simple stereotypes and values of the Valentino film, and her infatuation with success makes her easy prey for Waldo's line in the theater and his Kessler story. Later, she accepts Dillhoefer's offer to stardom, seeing the dangerous stunt as an easy route to unparalleled fame. The self-proclaimed "'It Girl' of the Skies," naively thinking in terms of movie magazines, makes 
a fatal error in judgment. Ezra makes a similar tragic error, overestimating his abilities and overextending himself in a search for glory. Waldo, though more qualified than both of them, is still pushed by that need for fame, and, in his blind pursuit of it, as vulnenable and foolish as either of his two friends.

Not only are the motives of the characters less simple and attractive than in the conventional success narrative, but so is the goal they seek. Waldo Pepper shows that heroism and success have a dark, complex obverse and that unhappiness and danger are as much a part of the phenomenon as the traditionally celebrated joy. The pre-title sequence is the first indication of this. We are shown a series of still photographs, alternately encountering a pilot striking a gallant pose and then a crashed plane. The pilots seem members of a heroic race, their achievements romanticized by time, but the crashed planes, bringing images of death, momentarily puzzle. Their conjunction with the pilots' faces suggests that the death and the heroism go hand in hand. This same idea is also intimated in the first encounter with Axel, the rope-climbing sequence, and the Hollywood stunt scenes. Each is played for farce, and thus the threat of death or pain is sublimated, but nonetheless present. Axel, as Waldo admits, could die in the attempt to land the wheelless plane; Waldo could have been killed in the crash into the barn; and Waldo or Axel could have been seriously hurt in the stunt scenes. We do not worry 
about the characters because subconsciously we do not expect them to suffer; convention prohibits it. But the danger implicit in these scenes becomes explicit later, specifically in Mary Betn's fall, Ezra's crash, and Axel's parachute jump, and the conventions which gloss the dangen in the comic scenes no longer apply. The audience sees that death and danger are an integral part of the pursuit of success. Mary Beth's fall and Ezra's crash shock us with their unexpectedness, and chill the warm glow associated with success. We assume Waldo will rescue her and somehow save Ezra, and are puzzled when he does not. The old rules no longer seem to apply, and the nature of heroism is altered. Thus, during Axel's parachute jump there is real tension because death is now a distinct possibility in Hill's analysis of the drive towand success.

The relationship between the individual and society differs in this film also. Traditionally, the hero's actions benefit society (e.g., a war hero, a business hero, a political hero) or edify it (a sports hero, or someone who accomplishes an unusual feat), and the hero enjoys a privileged relationship with his fellow citizens. We need only think of the special status and reverence accorded figures as diverse as MacArthur, Grant, Lincoln, and Daniel Boone to confirm the point. In Waldo Pepper, that relationship has changed; society, in its manifestation as the crowd, is no longer worthy of any effort or respect. In this film, as in Slapshot, the crowd represents the cowardly, greedy, and 
selfish aspects of humanity. It flocks to and follows heroes not because of their accomplishments, but because it thrives on their energy and achivements, using them as a stimulus for their own dreams. The crowd is not really interested in the individual, only in the vicarious stimulation provided by the individual's actions. As Dillhoefer says, they will come only if "they're sure you're gonna die." This search for thrills always motivates the crowd. In Waldo's initial confrontation with Axel, for example, the crowd idiotically cheers Waldo's arrival and then Axel's near fatal crash. The need for vicarious stimulation is comically glossed here, but is enlarged upon in several later scenes. The crowd chants gleefully during Kessler's "Death Spin," and later will be morbidly vulturous at Ezra's crash. 5 Also, the draw for Werfel's film will be the possibility of excitement and danger, the crowd again demanding thrills for entertainment.

The situation exists, the film suggests, because of the distorting nature of the myth-making process. The myth celebrates rare moments of courage and achievement, such as Kessler's battle, serving as an inspiration to the listeners; but, in the modern era, myth-makers like werfel have reduced the extraordinary to the common, making it palatable pabulum for the masses. The artists who have recorded the deeds of heroes have become con artists, eliminating the danger and loneliness of the heroic phenomenon to make it more attractive to consumers. The public, having fallen in love with 
a glittering image, no longer sees success and heroism as something distant and difficult; instead it finds them a cheaply and painlessly available source of pleasure and stimulation. The old hero-public relationship is seen in Waldo's relationship to Scooter, the farm boy. Waldo's feats represent something extraordinary to him, and, as the last shots of his face listening to the airplane make clear, he dreams of becoming Waldo. ${ }^{6}$ But that simple relationship becomes increasingly distorted as the film progresses. In the next sequence, the confrontation with Axel, we have the thoughtless worship of the hero. After waldo lands his plane and jumps from the cockpit, a man and a woman step forward with camera and snap his picture. They have fallen for the image of success, gravitating immediately to Waldo because of his appearance, not because he has done anything unusual or embodies (as he does for Scooter) a dream of transcendent flight. Waldo's appearance is preserved in a two-dimensional photograph, and it will serve as a pleasant reminder of an alternative to a mundane world, not an inspiration to rise above it. Mary Beth parallels these anonymous people, for she too longs for a dream which she does not understand. The world of the Hollywood film completely captivates her with its promise of a grandeur unavailable in her everyday life. The crowds at the fairs come for the same promise of thrills and excitement, content to live vicariously, satisfying their need for stimulation through the pilots' actions. ${ }^{7}$ And Waldo, too, is 
lured by the promise of glory and success. For all his intelligence, he cannot see that the myth of success remains as two-dimensional and false as Dillhoefer's air circus or a Hollywood film.

Catering to these people are the con artists: Waldo, Axel, Dillhoefer, and Werfel. Axel and Waldo benevolently manipulate the crowd, promising memorable excitement for five dollars. They sugar-coat what for them (and for us) is an ordinary experience, or, in Waldo's case, turn something dangerous (Axel's wheelless flight) into something entertaining. But they are amateurs compared to Dillhoefer and Werfel, who manage to take something ineffable and extraordinary and transform it into a commodity. So the film cuts from Waldo's wing walk, a spectacular moment in which he seems to transcend the world, to the circus and Dillhoefer's voice barking out superlatives. Waldo's experience (and the flight experience) has become an illusion of excitement, and the crowd's only interest is the novelty: Two spectators are disappointed because the stunt is not new. Hollywood is only a more sophisticated version of the air circus, an industry that specializes in creating illusions for the masses. Its charlatan nature is revealed in the behind-the-scenes look at filmmaking. The stunt scenes function not only as comic pieces, but also show the essential duplicity and disregard for human well-being that go into the making of a Hollywood illusion. The Western or adventure myths created by Hollywood are distortions 
manufactured by unthinking and occasionally egotistical people. In each of the scenes, Waldo and Axel's physical well-being is second to the demands of the shot or illusion, such as the Western star's conviction of his "grace." Werfel, the controlling figure of that environment, is the most sinister incarnation of the con artist. We first meet him as he stands before a screen watching outtakes of a crash sequence, his concern for the pilots incidental to his concern for the take's usefulness in the picture. Worse, Werfel actually believes in the holiness of his mission. When confronted by the ever empirical Waldo about the inaccuracy of details, Werfel replies that "anyone can provide accuracy, artists provide truth." Whereas Waldo, Axel, and Dillhoefer knowingly bilked the public, Werfel has duped himself as well as the masses; "It's all true," he says. We know that, as Kessler says, "It's all lies," but Werfel cannot distinguish between the fantasies he has created and the complex, ambiguous, and dangerous world that has provided the raw material for him.

Thus, in The Great Waldo Pepper, we once again have two stories interwoven. The traditional story traces Waldo's pursuit of the title of "the greatest flier in the world"; the ironic story created by combining the variations shows his slow disintegration in pursuit of success. By the time Waldo moves to Hollywood, he has discarded Maudie and any semblance of an ordinary life for a false dream. Waldo is a dupe of the cultural convention that happiness depends 
upon success; his pursuit of the ideal is a measure of his need for success and the hypnotic power of the dream.

The ending of the film, however, takes us beyond condemnation of the ideal of success; it shows us the nature and the cost of that success in a way that conventional films do not. On the set of Werfel's picture, Waldo meets Kessler, and suddenly his dream of success is exploded. Waldo expects Kesslen to be adored, famous, and rich; instead he finds an ordinary man given a job out of a misguided sense of charity. The illusion that sustained Waldo through the deaths of Ezra and Mary Beth must now be discarded; Waldo must find a new dream in which to believe. That proves possible, for, in his talks with Kessler, Waldo discovers that it was the onder, simplicity, beauty, and certainty of the transcendent moment that always attracted him; the search for money and fame was a mistake on his part, a confusion of money and values. Earlier, in describing his fight with Kessler, Waldo was asked if he were scared. "It was crazy," he replied, "but I was happy." Later, Waldo asks Kessler the same question. "No," the German replies, "everything was in order; the world made total sense." For, as Kessler said earlier, "life is clear for me up there alone. In the sky I found, even in my enemies, courage and honor and chivalry . . On the ground. . [he shakes his head]."

Both men realize that in that pure world of the air every battle was a test of one's individuality: victory a 
proof of one's right to existence; defeat was acceptable, for in it at least one's position was clearly defined. The two men seek in their final dogfight to recapture that transcendent moment, that brief space of happiness which seems, as Kessler says, "like a cheat" when compared to the rest of life, by testing themselves against each other. Waldo wins the fight but that is unimportant; it is the certainty of knowing the order and the exhilaration of the endeavor that matters. He pulls his plane alongside Kessler's, and the two men remove their goggles, seeing each other without modifying lenses in this momentarily perfect world. Then they salute, and that gesture, which has been hollow throughout the film (witness Waldo and Axel's mock salutes to each other and Waldo's final salute to Newt), takes on its original significance: a signal of respect. The dream has been realized, and Waldo decides to retain it. He looks down at the ground and then at the sky. He knows that a return to earth is only a return to the same old circus (Werfel's shout of "get a camera on them") or a return to serve as fodder for the vicarious dreams of the crowd (witness Newt's reaction to the fight). Waldo soars off into the sky, holding onto the perfect moment as long as possible. The sound of the engine is replaced by the sound of air rushing through the struts, and at last he seems to have transcended the mundane world.

But the audience cannot see Waldo's triumph in the same romantic light it would see a conventional triumph, 
for the price of that moment involves both physical and spiritual death. 8 In that final dogfight, waldo has literally become Madden, the fated World War I flier, divesting himself of his own identity and moving totally into the dream world of the past.

Existence in both the material and dream worlds is not possible, and so Waldo makes his choice for the dream, denying the material in his action. The role has taken over the man, and a return to earth, and an ending of the role, is not possible, for it would force another confrontation with the material existence that he sought to escape in the dream. He would end up like Kessler: forgotten and failed, certain only that life was a cheat. The film closes with out bittersweet perception that the rewards of heroic endeavor are indeed great, a joy and a beauty that exceed much on our ordinary earth, but that the costs, in terms of human expenditure, are equally great. The Great Waldo Pepper ends by reasserting the myth of heroism, but with an honesty that the older, conventional forms no longer contain.

\section{$\underline{\text { NOTES }}$}

I

Stanley Kauffmann, "Rubinstein, Redford, and Bolkan," The New Republic, 172, 22 March 1975, pp. 22, 33. Pauline Kael, "Rear Guard," The New Yorker, 51, 24 March 1975 , Pp. 94-99. Michael Buckley, rev. of The Great Waldo Pepper, Films in Review, 26, No. 4 (August 1975), pp. 245-46. Paul Zimmerman, "Outside Loop," Newsweek, 85, 17 March 1975, p. 93. 
2 Zimmerman claims that "screenwriter William Goldman - . cooks up one clever reversal of expectations after another to keep his lightweight vehicle airborne. . . . Goldman, Hill, and Redford are after something more than 'The Hardy Boys Go Flying,' but instead of creating characters and relationships we can care about, they go for Big Themes: Hero vs. the Bureaucrats.. . the exploitation of stunt fliers by Hollywood, and, of counse, the Meaning of Life. Overloaded with such heavy thiniking, the movie nosedives," p. 93.

Kauffmann writes that the film "bobbles two fine themes. . one: the romance of air war... two: the psycho-cultural change in the late 1920's when flying changed from derring-do to business, from stunting to airlines. Both of these themes are apt for film, both have some significance. Both are handled unsteadily," p. 22.

Kael writes that "Hill seems to be enamored of the idea of the hollowness of tragedy. . . Maybe we're supposed to take it as a comment on heroism, but it's more like a comment on eternal stardom. . there is also an attempt to latch on to the last-of-the-individualists glamourgimmick," p. 97. p. 9 .

3 Richard Shickel, "High Flying," Time, 24 March 1975 ,

4 In the published screenplay, William Goldman and George Roy Hill, The Great Waldo Pepper (New York, 1975), pp. 160-61, there is an excised scene in which waldo imagines himself as a triumphant aviator making up for Ezra's death. Waldo is recovering at Maude's farm and sits under a tree late at night. "He is very drunk and has no intention of stopping there"!

WALDO: Looks bad folks--looks real bad--

We realize now that WALDO isn't exactly talking

to himself--his right hand is held in front of

his mouth and it's a microphone. MAUDE steps

out on the porch, but he doesn't see her.

WALDO: I guess the Arctic wastes was too much for any man, even Pepper--[Drinks from bottle.] It was a crazy idea, folks. No man can fly alone around the world--[Drinks again.] It woulda made Lindbergh's solo flight across the Atlantic look like a puddle jump, but I guess it ain't to be--[A really long swallow.] We might as well return you to the studio--[Cocks his head.] Wait a sec--[Looks around.] $\overline{\text { Any of you }}$ fellas hear what I heard? [They didn't.] Just 
imagination, folks, sorry; anyway--[Breaks off again.] I could have sworn I hear--[Shrugs.] Must be getting old and--[He makes a rumble.] No--dammit, that is a motor--[Realiy makes a loud motor sound now.] Good people, I got tears in my eyes--[He does.] It's him,

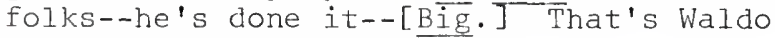

Pepper up there, everybody!

MAUDIE stands on the porch. She is crying. WALDO turns and suddenly sees her. He just stares.

5 Kael criticizes Hill, accusing him of contempt for the common man down below. She sees that attitude as part of Hill's "big city" slickness, and denies that it has an integral role in the film, p. 97.

6 As Kael says, "the boy is blond and old-movie freckled, and he's going to grow up to be just like waldo, whom he idolizes; we know we're meant to think that the boy is Waldo as he once was," p. 97.

7 Dillhoefer is impatient to leave the police station after Mary Beth's death because "an accident really brings out the people."

8 The last photo indicates that waldo died during or shortly after the dogfight. 
CHAPTER VI

CONCLUSION

Hill continues to grow as an artist, exploring new dimensions of the American experience rather than simply repeating his past successes. His most recent film, Slapshot, looks at the American obsession with sports, and once again finds a world where individuals dissipate their strengths chasing ephermeral cultural dreams.

The film is typically ironic. Reggie Dunlop and Ned Braden, the protagonists, start as likeable characters: funny, human, talented, and motivated by a recognizable cultural dream. They retain that status throughout, mostly because their opponents (e.g., Dr. Hook), the team manager, the owner, and the players (e.g., the Hansons) are caricatures of sports figures and hangers-on. And most people identify with them throughout, as attendance at a screening of the movie demonstrates. But they are also undercut. Reggie lacks any sensitivity or understanding, as is demonstrated in his relationship with Lily Braden. He is crude and selfish, not a tough guy with a heart of gold. He callously manipulates his players, even though the success of his wonk (e.g., "Killen" Carlson) dismays him. And he plays the hard-living, tough-bitten hero for so long that the role 
gradually takes over the man. Reggie cannot be honest, or kind, or sensitive because to do so would be to violate his rugged individual's code. In the climactic confrontation with Braden, he makes a futile attempt. He shouts out his apologies into the woods, promising to play clean hockey and reform his character. Ned does not answer, and so Reggie slips into his old habit of manipulative rhetoric and story-telling, even though his remarks, an occasional "no, that's bull----," indicate that he is trying not to. But when Braden still does not answer, Reggie resumes the old role; he starts taunting Braden about the runaway Lily, trying to bring Ned back under his control.

Ned is as shallow as Reggie. He abuses his wife, cheating on her, and nearly driving her to the point of a mental breakdown. Lily is a painful reminder of the questionable nature of his dream, the sanity and the love she demands too much a burden on him. Like Reggie, Ned cheats on his wife because it is an easy way to prove his mascuIinity. Also, his performance at the end undermines his credibility. It is difficult to see him as a hero when he willingly adopts Reggie's belief that success justifies any lapses of character. Braden is the young Reggie, bound forever to the dream and all its debilitating traps, and he will end up like Reggie, alone and lying to himself.

Once we perceive that the characters are not twodimensional figures, we see that the story is more than a conventional sports saga. It traces the gradual decline of 
two men duped by the cultural convention that success equals happiness. Both Reggie and Ned are outsiders, dwelling on the edge of society, and seeking fulfillment through achievement of a socially approved goal: success in sports. Although they begin with an identical goal and shared assumptions of how to reach it, they soon drift apart. Reggie sees in the imminent collapse of the hockey team an end to the opportunities to prove himself, to gain the success he desires, and consequently begins a campaign to keep alive the team and the possibility of eventual triumph. He struggles to overcome the incompetence of his players, the owner's indifference, and his own scruples, eventually gaining success when he throws away any pretense of character or dignity. Ned is similar to Reggie since he, too, has a dream of success, hoping to prove his distinctive individuality by becoming a hockey star. He has given up an easy, comfortable Iife because it cannot provide the satisfaction of the acclaim earned in the arena. Ned differs with Reggie, though, on the method of attaining success. He will not compromise himself, or his principles, refusing to "goon it up" for Reggie. But he ultimately comes around to Reggie's viewpoint that success justifies any action. After Reggie "corrupts" Lily Braden, turning her into one of the crowd, Ned snaps. He casts dignity aside, performing a striptease as sensational as Reggie's violence. Instead of shattering Reggie's world, he accepts it, as the victory march with the trophy indicates. In the final scene, Ned, 
now wearing dark glasses, perhaps indicative of his circumscribed vision, now merrily joins Reggie in the lead car. He has become part of that world, in effect admitting that success is worth any price.

The audience, however, cannot approve that philosophy, for the "success" is empty and valueless. Reggie will never have the life with Francine that he desires, and must lie to himself, as he has done throughout the picture, that his triumphs will bring her back. Ned has not resolved any of his problems, and his similarity to Reggie makes us withdraw our sympathy to him. The two men are, like Waldo, Butch, and Sundance, victims of the cultural exaltation of success. Reggie cannot see himself as an individual unless he continualiy proves his right to that attention; he cannot be "Reggie Dunlop" and be happy; he must be "Reggie Dunlop--success" in order to be satisfied. Devotion to that goal blinds him to reality, and his life will remain an unhappy pursuit after a dream. Ned, like Reggie, is caught in the same trap and doomed to the same end.

Slapshot shares a basic theme and structure with all of Hill's later work. There are the traditional stories: Western elegy, action adventure, success story, and caper film; and there is also the untraditional element. The stories invariably involve an outsider, someone discontent with the prevailing social complacency, who attempts to invest his life with meaning through the realization of an American cultural dream. The pattern is the same in each 
film. The protagonist defines a traditional goal; he achieves that goal, usually after much struggle; and then discovers, or has an opportunity to discover, the meaninglessness of his success. His efforts fail, or lead to unexpected results, because of the destitution or falsity of the motivating dream. Attaining success, or heroism, or the perfect family does not bring the satisfaction and selfworth assured by the dream; such hopes were illusory, and efforts spent realizing them valueless. The narratives reveal the essential hollowness of these cultural beliefs. The basic theme of the films is the inadequacy of the American dream. The culture urges individuality, a distinction of the self from the mass, and seems to reward those who distinguish themselves through superior endeavors. Hill's characters respond intuitively to this pressure, for all are dissatisfied with their present existence, and, except for Billy Pilgrim, seek, through some kind of test, to achieve the status of exceptional individual. They each have an arena in which to prove themselves: the outlaws and the con men, crime; Waldo, his air circus; and Reggie, his arena. Value in life comes, they seem to believe, not from existing, or through communication with others, but through continued proof of their right to fulfill the roles-success, family man--exalted by the society. But the culture fails them. The conventions and beliefs adopted by the characters ane not strong enough to sustain them in an increasingly complex modern world. The American emphasis 
on individuality has led to a false search for paradisaic happiness, a deleterious obsession with self at the expense of community

Hill's films always contain both stories, and our understanding of them arises from our perception of the irony present and a comparison of the two narratives. The films are ironic, for they appear to extol traditional values through conventional narratives while actually undercutting those values. By working variations of the genre conventions, Hill stimulates us to look more closely at them, to question the films' traditional assumptions. Hill, by focusing attention on the conventional narrative and a dissenting interpretation of it, makes possible an evaluation and understanding of our cultural beliefs.

Varied and interesting, the result of constant interaction between the artist and society, Hill's films stand as one of the better cinematic examinations of the American culture. And it appears they can retain their high standing in the future. He has not yet exhausted his basic themes and patterns, and is developing new concerns, both indications that he is still capable of continued growth as an artist. 


\section{BIBLIOGRAPHY}

Andrew, J. Dudley. The Major Film Theories: An Introduction. New York: Oxford University Press, 1976.

Arnehim, Rudolph. Art and Visual Perception: A Psychology of the Creative Eye. Rev. edition, Berkeley: University of California Press, 1974.

: Film as Art. Berkeley: University of California Press, 1957.

Balázs, Béla. Theory of the Film: Character and Growth of a New Ant. Trans. Edith Bone. 1952; rpt. New York: Dover Press, 1970.

Baxter, John. "The Gangster Mind." Crossroads to the Cinema. Ed. Douglas Brode. Boston: Holbrook, 1975, pp. 292-303.

Bazin, Andre. What is Cinema? Vol. 1. Ed. and trans. Hugh Gray. 1958-65; rpt. Berkeley: University of California Press, 1967.

- What is Cinema? Vol. 2. Ed. and trans. Hugh Grey. $1958-65$; rpt. Berkeley: University of California Press, 1971.

Braudy, Leo. The World in a Frame: What We see in Films. Garden City, N.Y.: Anchor, 1977.

Casebier, Allan. Film Appreciation. New York: Harcourt, Brace, Jovanovich, 1976.

Durgnant, Raymond. Film and Feelings, 1967 ; rpt. Cambridge, Mass.: Massachusetts Institute of Technology Press, 1971.

Eisenstein, Sergei. Film Form: Essays in Film Theory. Ed. and trans. Jay Leyda. New York: Harcourt, Brace, Jovanovich, 1949 .

- The Film Sense. Ed. and trans. Jay Leyda. New York: Harcourt, Brace, Jovanovich, 1942. 
Everson, William K. "Seventy Years of Westerns." CrossRoads to the Cinema. Ed. Douglas Brode. Boston: Holbrook, 1975, pp. 280-91.

Geduld, Harry M., ed. Film Makers on Film Making. Bloomington, Ind.: Indiana Üniversity Press, 1967.

Hurley, Neil P. Towards a Film Humanism. 1970; rpt. New York: Delta, 1975 .

Huss, Roy, and Norman Silverstein. The Film Experience: Elements of Motion Picture Art. New York: Delta, $\overline{1968 . ~}$

Kaminsky, Stuart. American Film Genres: Appraoches to a Critical Theory of Popular Film. IN.P.: Pflaum, 1976.

Kelman, Ken. "The Reality of New Cinema." The New American Cinema: A Critical Anthology. Ed. Gregory Battock. New York: Dutton, 1967, pp. 102-04.

Lane, Michael, ed. Introduction to Structuralism. New York: Basic Books, 1970 .

MacBean, James Roy. Film and Revolution. Bloomington, Ind.: Indiana University Press, 1975.

Macgowan, Kenneth. Behind the Screen: The History and Technique of the Motion Picture. New York: Delta, 1965.

Macksey, Richard, and Eugenio Donato, eds. The Structuralist Controversy: The Languages of Criticism and the Sciences of Man. 1970; rpt. Baltimore: The Johns Hopkins University Press, 1972.

Mast, Gerald. A Short History of the Movies. 2nd Ed. Indianapolis: Bobbs-Merrill, 1976.

Monaco, James. How to Read a Film: The Art, Technology, Language, History, and Theory of Film and Media. New York: Oxford University Press, 1977.

Nachbar, Jack. Focus on the Western. Englewood Cliffs, N.J.: Prentice-Hall, 1974.

Robinson, W. R. "The Movies, Too, Will Make You Free." Man and the Movies. Ed. W. R. Robinson, 1967; rpt. Baltimore: Penguin, 1969.

Simon, John. Movies into Film: Film Criticism 1967-1970. New York: Delta, 1971. 
Sklar, Robert. Movie-Made America: A Cultural History of American Movies. 1975; rpt. New York: Vintage, 1976.

Solomon, Stanley J. Beyond Formula. New York: Harcourt, Brace, Jovanovich, 1976 .

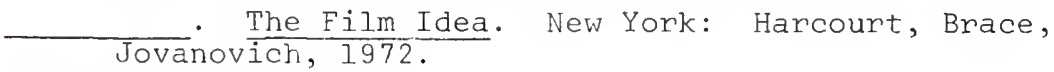

Whitehead, Alfred North. The Concept of Nature. 1920 ; rpt. Cambridge: Cambridge University Press, 1971.

Wollen, Peter. Signs and Meaning in the Cinema. 3rd ed., rev. Bloomington, Ind.: Indiana University Press, 1972.

Wood, Michael. America in the Movies: Or, "Santa Maria, It Had Slipped My Mind!" New York: Basic Books, 1975.

Wood, Robin. "Realism and Revolution." Film Comment, MayJune 1977, pp. 17-23. 
Edward Francis Shores was born in Binghamton, New York, on July 29, 1947. He attended local schools and then entered the State University of New York at Binghamton. Studies there were interrupted by two years of service in the United States Navy. Mr. Shores completed his undergraduate studies in January, 1972, and entered the University of Florida in September, 1972, enrolling in the English graduate program. He received his master's degree in March, 1974, and then took a year off, 1975-76, to teach at Brevard Community College, Melbourne, Florida. In January, 1976, he married Shirley Wagner, and now resides in Melbourne, Florida, where he continues his studies in film and literature. 
I certify that I have read this study and that in my opinion it conforms to acceptable standards of scholarly presentation and is fully adequate, in scope and quality, as a dissertation for the degree of Doctor of Philosophy.

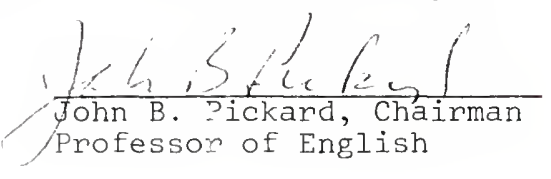

I certify that I have read this study and that in my opinion it conforms to acceptable standards of scholarly presentation and is fully adequate, in scope and quality, as a dissertation for the degree of Doctor of Philosophy.

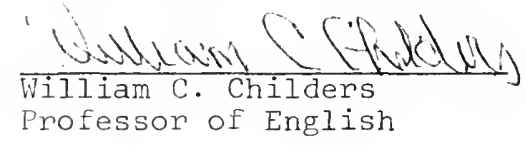

I certify that I have read this study and that in my opinion it conforms to acceptable standards of scholarly presentation and is fully adequate, in scope and quality, as a dissertation for the degree of Doctor of Philosophy.

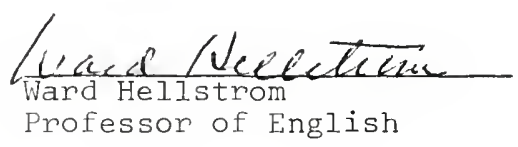

I certify that I have read this study and that in my opinion it conforms to acceptable standards of scholarly presentation and is fully adequate, in scope and quality, as a dissertation for the degree of Doctor of Philosophy.

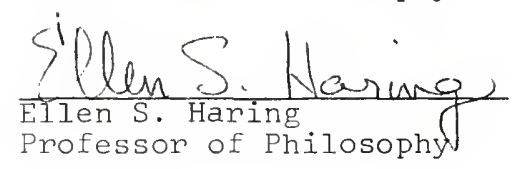


I certify that I have read this study and that in my opinion it conforms to acceptable standards of scholarly presentatly and is fully adequate, in scope and quality, as a dissertation for the degree of Doctor of Philosophy.

$$
\frac{\text { Jjalky } 7 \text { deakin }}{\text { Motley F. Deakin }}
$$

This dissertation was submitted to the Graduate Faculty of the Department of English in the College of Arts and Sciences and to the Graduate Council, and was accepted as partial fulfillment of the requirements for the degree of Doctor of Philosophy.

August 1977

Dean, Graduate School 
UNIVERSITY OF FLORIDA

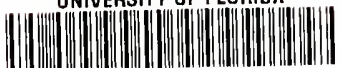

31262086662466 